\title{
أثر القرينة الطبية في إثبات الإرث
}

\author{
في الفقةه الإسلامي

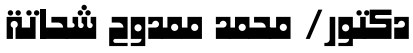 \\ مدرس الفقه الإسلامي وأصوله \\ كلية الآداب - جامعة المنيا
}

مقدمة:

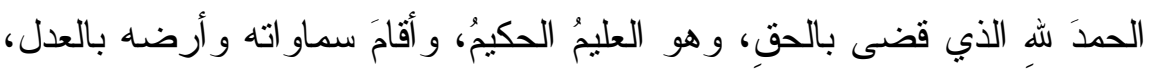

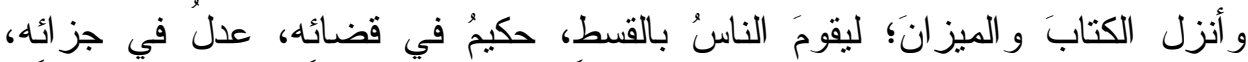
و الصلاة و السلام على من أنزل عليه الكتاب بالحق؛ ليحكمَ بين الناس بما أر اه اهلهُ الله،

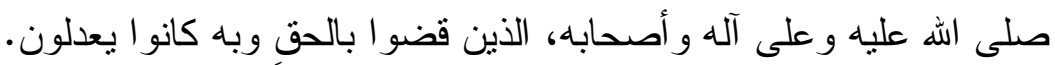

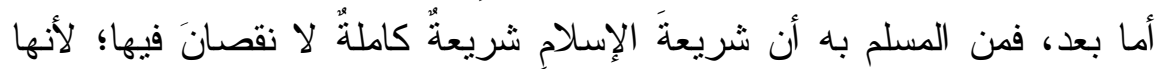

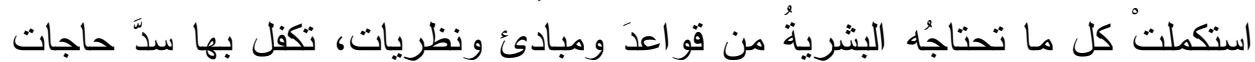

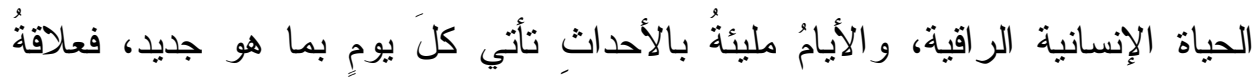

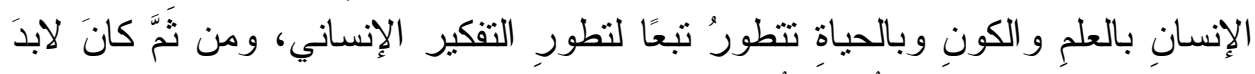

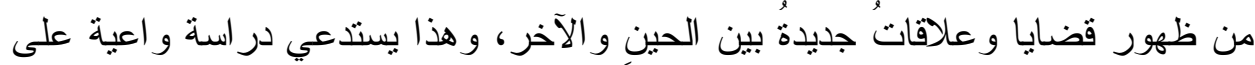

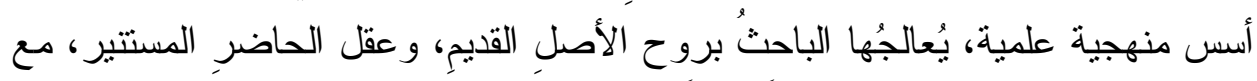

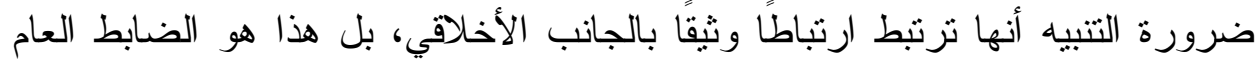
للبحث العلمي في الإسـام للقضايا المعاصرة، وغيرها من القضايا.

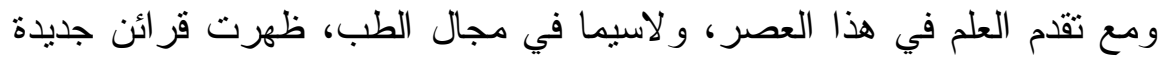

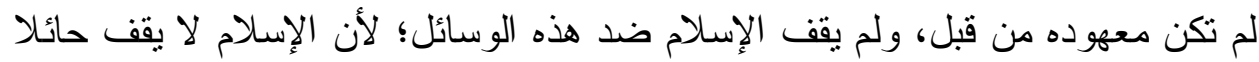
أمام كل جديد.

لهذا أردت من هذا البحث أن ألقيَ بالظله علي تلاك القرائن الطبية الحديثة، وأثزها على الإرث لذا جاء هذا البحث بعنوان: "أثز القرينة الطبية في إثبات الإرث في الفقه

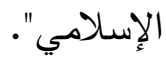
وقد جاء هذا البحث في مقدمة وتمهيد وثلاثة مباحث ... 


\section{تمهيد :}

ماهية القرائن الطبية ومشرو عيتها وضو ابطها أولاً: تعريف القرائن :

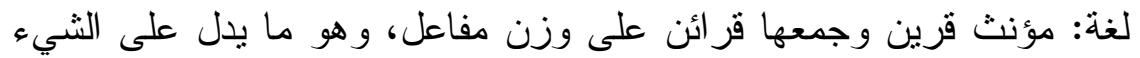

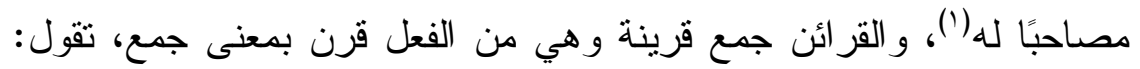
قرنت بين الحج و العمرة، أي: جمعت بينهما بإحر ام و واحد (؟).

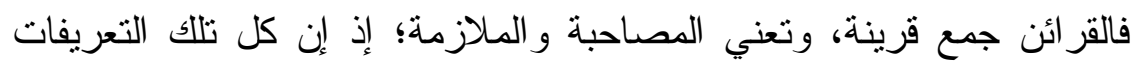

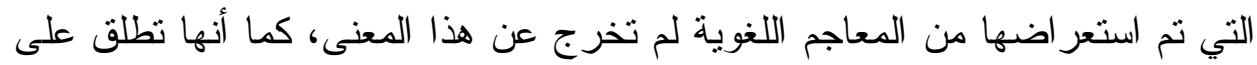

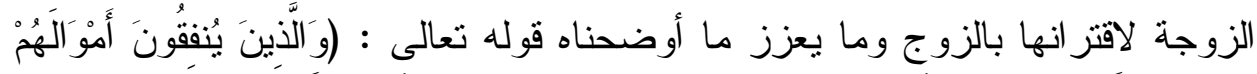

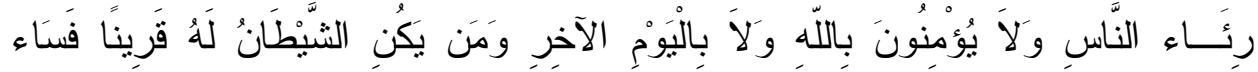

على أن المعنى المراد من تلاك الآية في كلمة قرين هو المصاحب أو الصاحب.

تعريف القرائن في الفقه الإسلامي: القرينة بمعنى المفاعلة وجمعها قرائن على

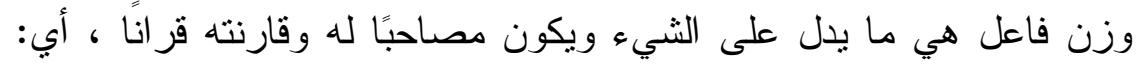

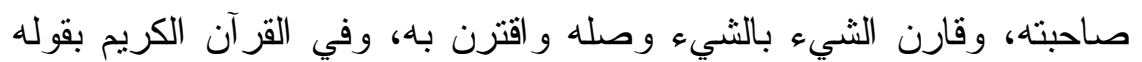

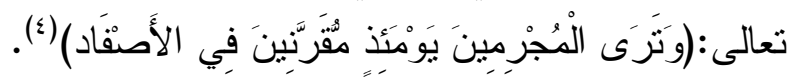

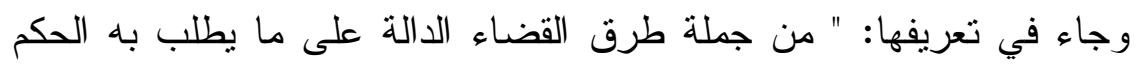
دلالة و اضحة بحيث تصبر في المقطوع بهاء فئ.

وقد عرّها الأستاذ مصطفى الزرقا بأنها كل إمارة تقارن شيئًا فتنل عليه(آ).

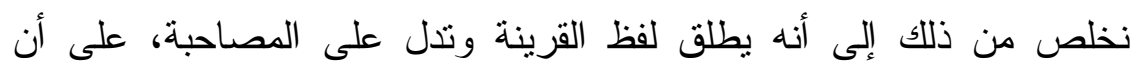
القرينة في الموضوع الذي نحن بصدده تعني الإمارة البالغة حد اليقين .

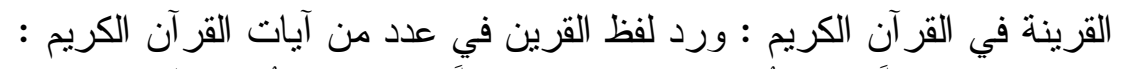

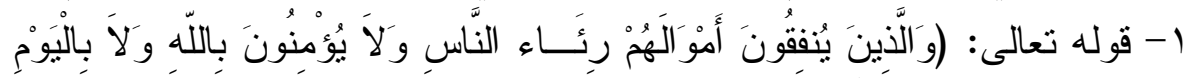

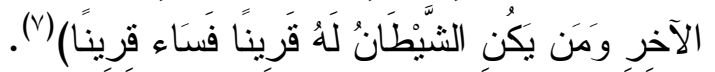

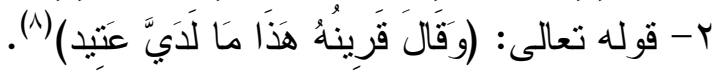




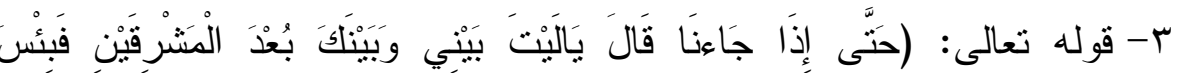

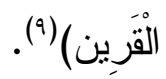

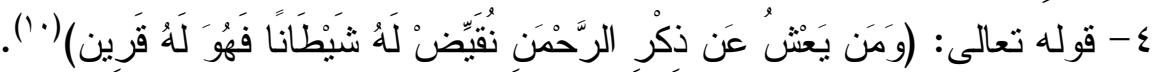

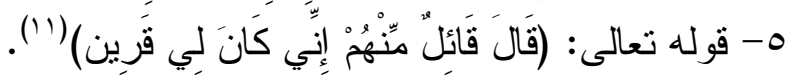

ومن خلال كل الآيات تعني كلمة القرين الخليل والصاحب، أبي الملازم

$$
\text { للإنسان، أي: المقترن بالإنسان و لا يفارقه . }
$$

تعريف القرينة في القانون المصري : ورد تعريفها في القانون المصري بأنهان بانها:

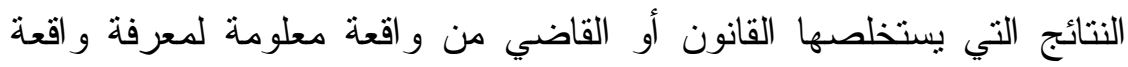

$$
\text { مجهولة (ir) }
$$

وقد عرّها الققه المصري بأنها استتناج الواقعة المطلوب إثباتها من واقعة

هذا وقد عرّفها البعض الآخر بأنها استخلاص المجهول من معلوم عن طريق

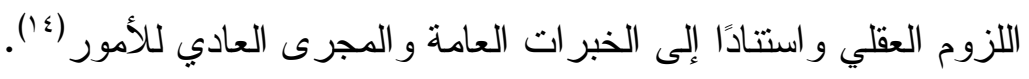

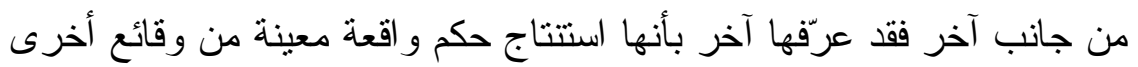
وفقًا لمقتضيات العقل و المنطق (10).

وحول التعريفات التي تم إير ادها يمكن القول بأنها كلها تدول حول معنى واحد

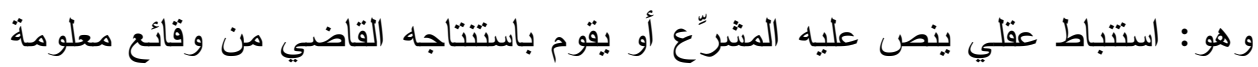

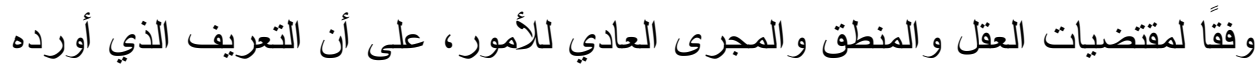
المشرِع المصري و أثنار إليه كتاب القانون لا يختلف عن التعريف الذي أورده المشرِّع السوداني في قانون الإثبات الحالي لسنة ـ9 99 ام . ثانيًا: مشروعية القر ائن الطبية : لقد اختلف الفقهاء في حكم العمل بالقرائن القوية، و اعتبار ها وسيلة من وسائل الإثبات على قولين : الإن القول الأول: جواز العمل بالقرائن والحكم بها: و إلى هذا القول ذهب ابن

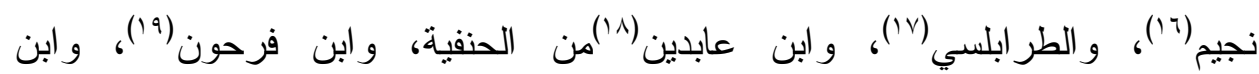

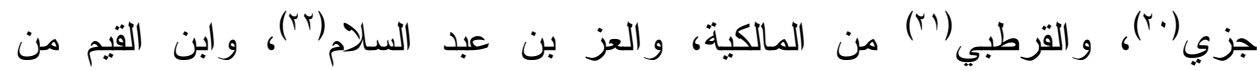


فالمالكية برون الأخذ بالقر ائن في كل الاعاوى مستندين بحديث الرسول صلى

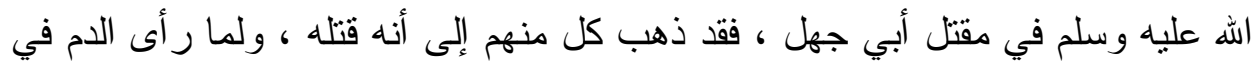

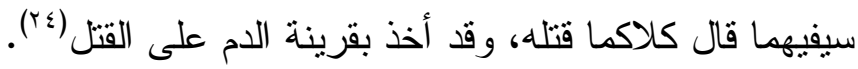
أما الثافعية فلم تدل كتب المتقدمين منهم على إعمال القر ائن ماعدا ما أورده

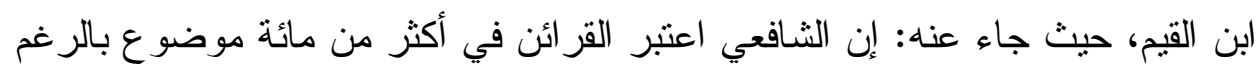
من أنه أبعد الناس عن الأخذ بهاء(ror). على أن الحنابلة يجيزون الأخذ بالقرائن في مواضع كثيرة، ومن أكثر الآخذين

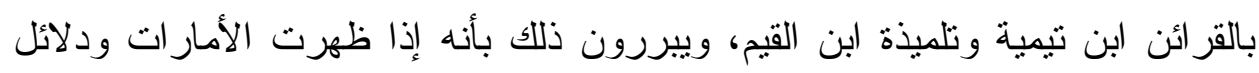

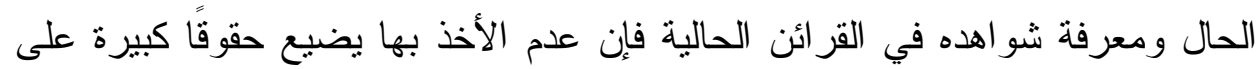
أصحابها، فالبيّّنة اسم لما يبين الحق ويظهره وهن وهن خصها بالثاهدين لم يوف مسماها حقه ، فالثار ع لم يلغ القر ائن (ب؟r).

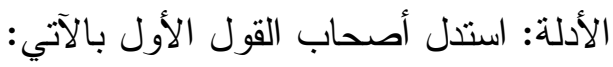

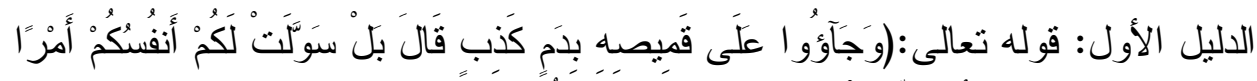

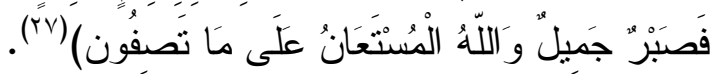
وجه الدلالة: أن إخوة بوسف - عليه السلام - لما أتو ا بقميصه إلى أبيهم تأمله فلم ير فيه خرقاً و لا أثز ناب فاستدل بذللك على كذبهم (r^).

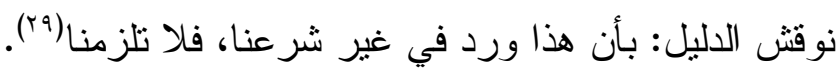

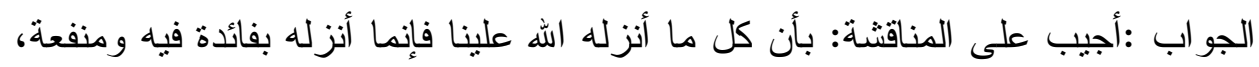

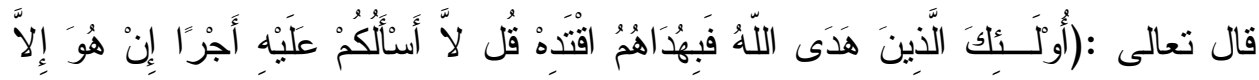

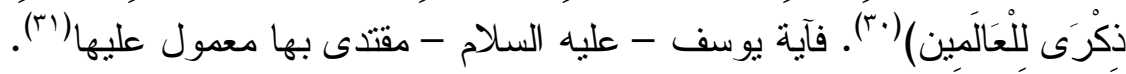

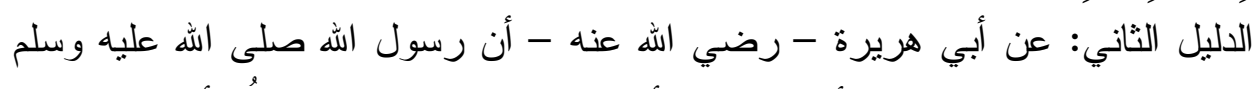

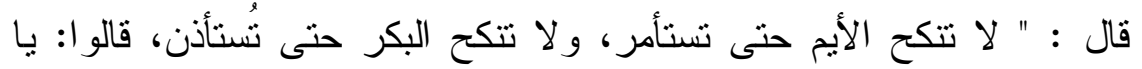

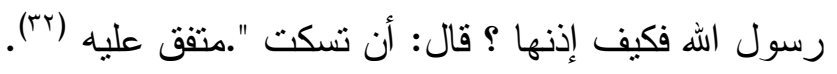

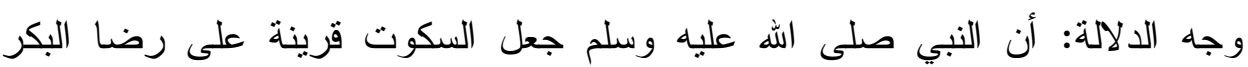

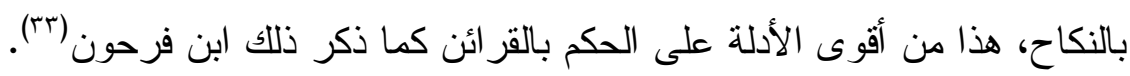

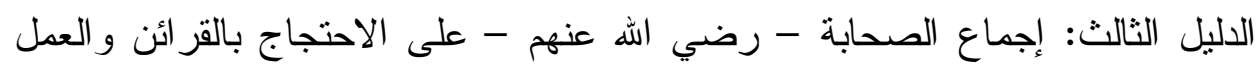

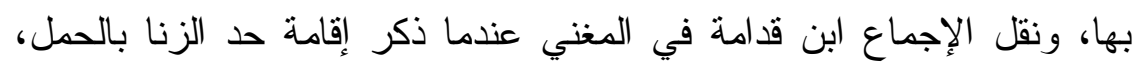


و هو قرينة على فعل الزنا قال: " وهذا قول سادة الصحابة، ولم يظهر لهم في

عصر هم مخالف، فيكون إجماعًا " (ع مَ).

ويقول ابن فرحون : " حكم عمر بن الخطاب- رضي الهه عنه - و ابن مسعود

وعثمان - رضي الله عنهما - و لا يعلم لهم مخالف بوجوب الحد على من وجد فيه

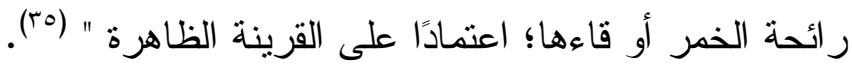

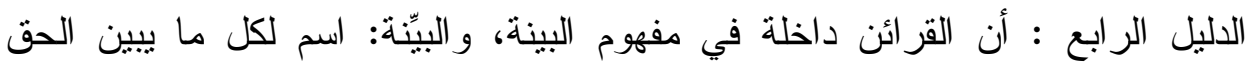

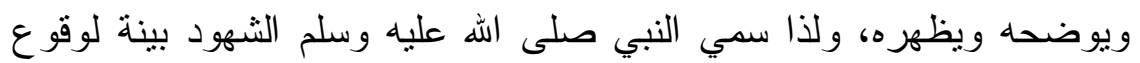

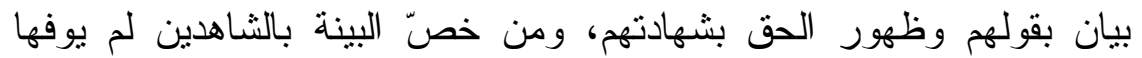

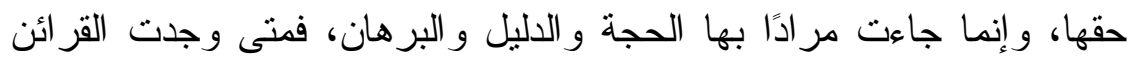

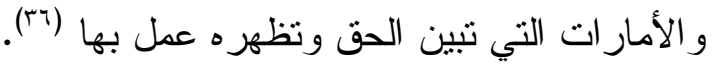

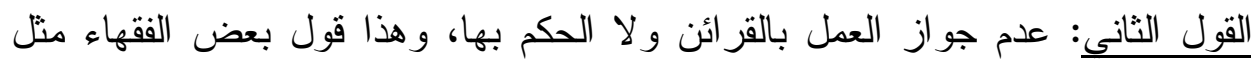

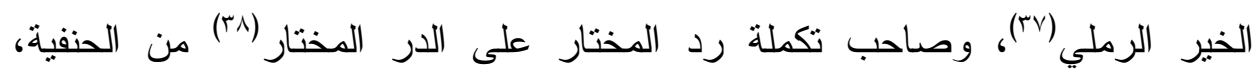

و القر افي من المالكية ("ra). فالحنفية يرون أن القرائن غير صالحة لكي تنبى الأحكام عليها؛ لأن طرق الإثبات تعتبر قد وردت حصرًا ولم تكن القرائن من بينها. على أن بعض فقهاء الحنفية

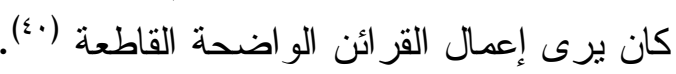
الأدلة: استدل أصحاب هذا القول بأدلة منها: الدليل الأول: قوله صلى الله عليه وسلم في قصة المتلاعبين: " إن جاءت به أكحل بله

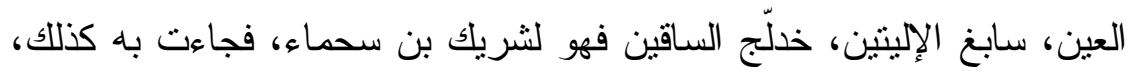

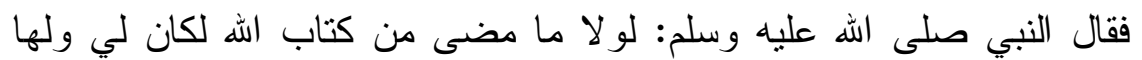

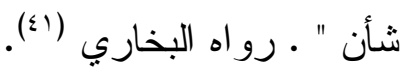
وجه الاستدلال: أن الني صلى الله عليه وسلم لم يعمل بقرينة الثبهة مع قوتها، ولم

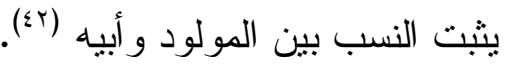
نوفش الدليل: بأن النبي صلى الله عليه وسلم لم يعتدّ بالثبهة لوجود اللعان،

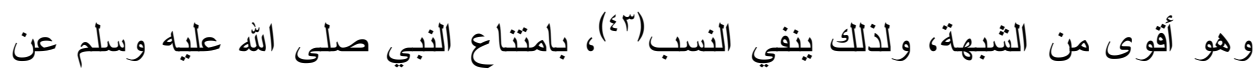

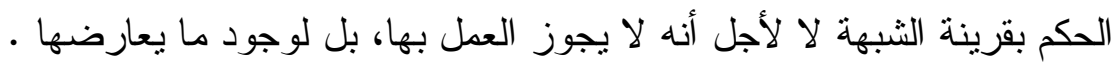


الدليل الثاني: أن القر ائن ليست مطردة الدلالة؛ لاختلافها قوة وضعفًا، فالقر ائن قد تبدو

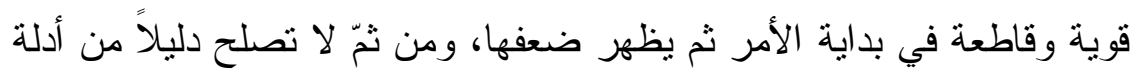

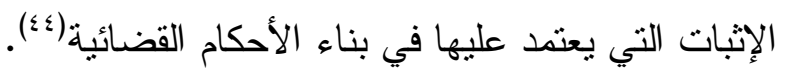

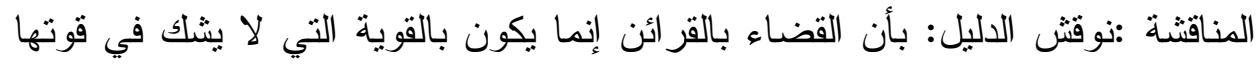

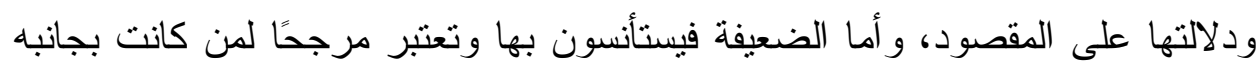

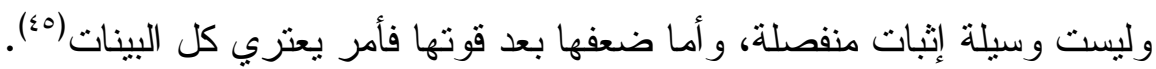

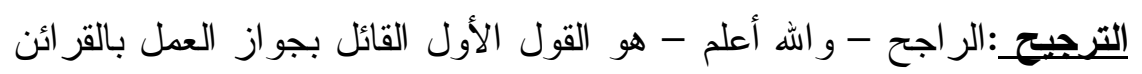

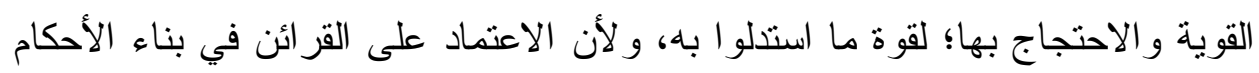

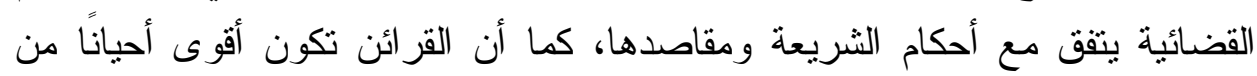

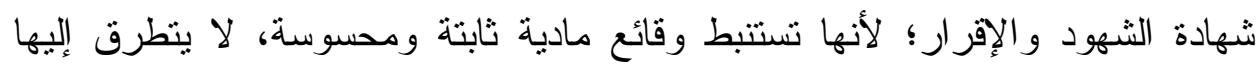
الكذب، وتعتمد على الاستتباط العقلي و المنطقي (Tء).

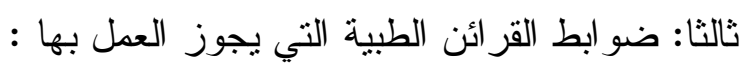

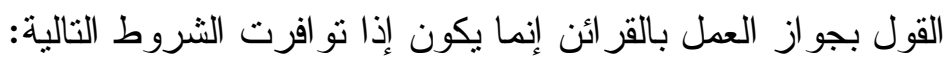

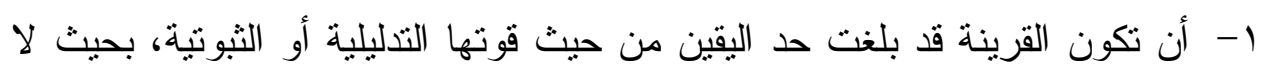

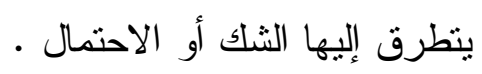
r- أن تكون القرينة قطعية في دلالتها على الأمر المقصود، أو الواقعة المطلوب إثباتها. r- يجب أن تكون هنالك واقعة ثابتة والتي تتمنل في الأمارة أو العلامة أو الدلالة،

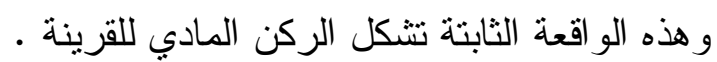
ع - يجب أن تكون عملية الاستتباط متفقة مع العقل و المنطق، من حيث استتباط النتائج من المقدمات، و هذا هو الركن المعنوي للقرينة .

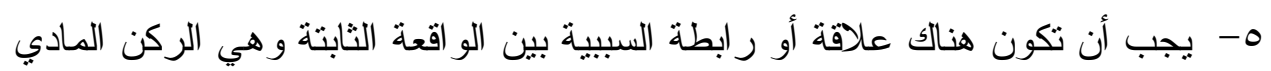

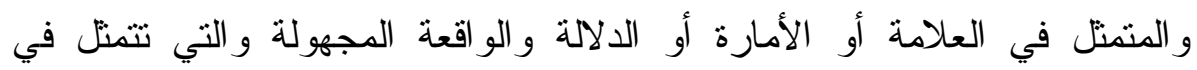

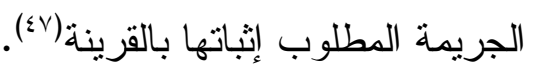


المبحث الأول :دور القرينة الطبية تقسيم الميراث مع وجود الحمل

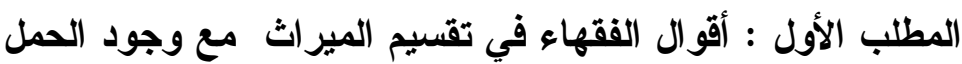
اختلف العلماء في مقدار الموقوف للحمل؛ إذ إن الحمل لا بعلم حقيقته إلا اله وهي تعالى، وتتجاذبه احتمالات كثيرة من حياته، وموته، وتعدده، وكونه ذكر ا، أو أنثى فنتج

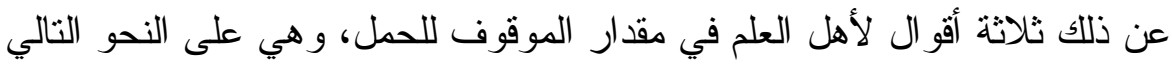
القول الأول: أنه يوقف الأحظ للحمل من نصيب ذكر واحد أو أنثى واحدة، عَنْ أَبي

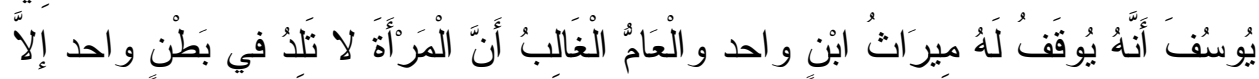

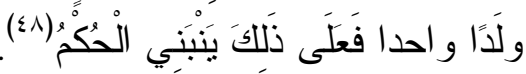
ويؤخذ على هذا الر أي أن و لادة أكثر من واحد كثير ، فيأخذ حكم الغالب والاكتفاء

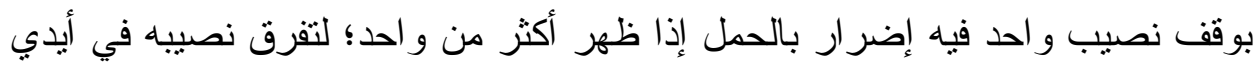

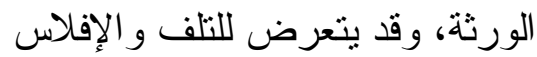
القول الثاني: نعامل الحمل بالاحظ ومن معه من الورثثة بالأضر مطلقًا؛ فمن كان من

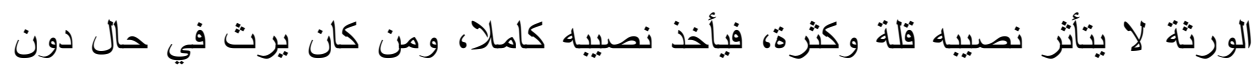

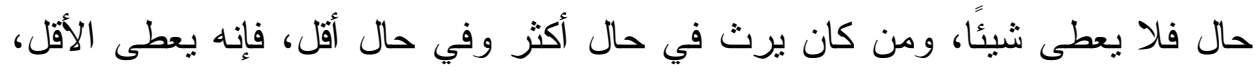

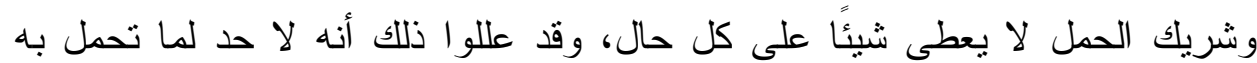
المر أة وقد وجد في النساء من تلا أكثر من اثثين وهذئ هذا مذهب الثافعية. القول الثالث: يوقف الاحظ للحمل من نصيب ذكرين أو أنثيين وهذا مذهب الحنابلة هذه الأفو ال الثناثة مبنية على الاحتياط وان اختلفت طريقة كل مذهب فعند الحنابلة الاحتياط أن يوقف للحمل الأكثر من ميراث ذكرين أو أنثيين وعند الثافعية الاحتياط

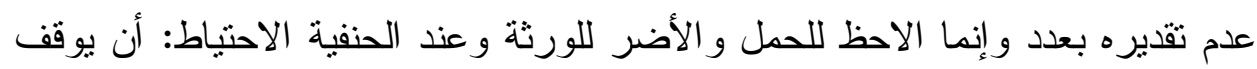
له الأكثر من مير اث ذكر أو أنثى ويؤخذ كفيل لندارك مالو حصل نقص فهي كلها تتفق وانق

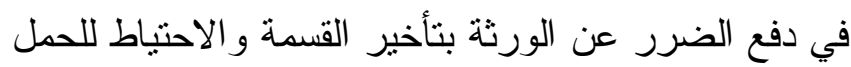

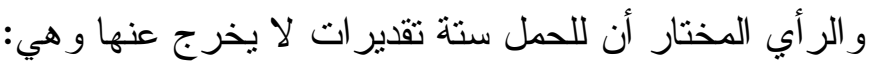

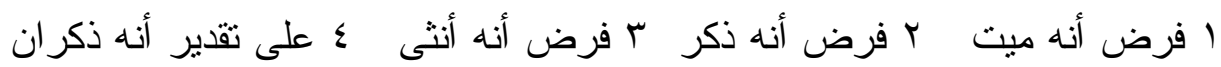

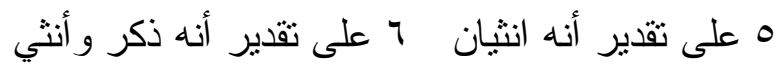

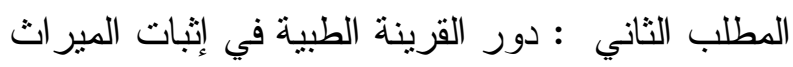


لقد تقدم الطب في هذا المجال تقدما ملحوظا فهنالك يقين جازم بحدوث الحمل وفق

$$
\text { وسائل طبية عن عدة طرق منها: }
$$

أولًا: تشخيص الحمل عن طريق فحص الدم، وذللك عن طريق أخذ عينة صغيرة من من فا:

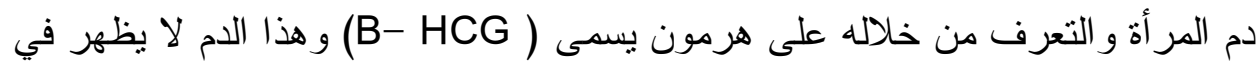
دم المرأة إلا عند حدوث الحمل، ويظهر حتى قبل انقطاع الدورة الدموية، وشعور المر أة بعلامات الحمل، وهذا الفحص يعطى نتائج مؤكده غير قابلة للخطأ من الناحية الطبية إلا إذا كانت المرأة تشتكي من حالات نادرة، مثل ورم على المبيض يفرز

$$
\text { هرمون ( (B) }
$$

ثانيًا: تشخيص الحمل عن طريق تحليل البول، إذ إن البويضة الملقحة تفرز هرمون الحمل ( BCG) الذي يظهر في بول المرأة، ويمكن معرفه وجود هذا الهرمون

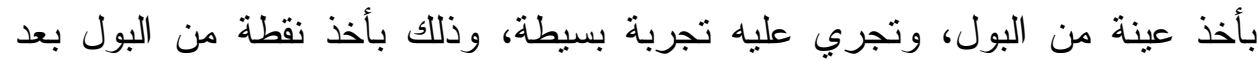

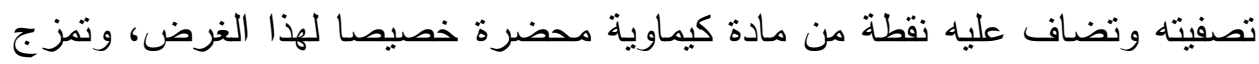
النقطتان معًا وتظهر النتيجة خلال دقيقتين ويباع في الصيدليات أجهزة صغيرة لهئ لاختبار

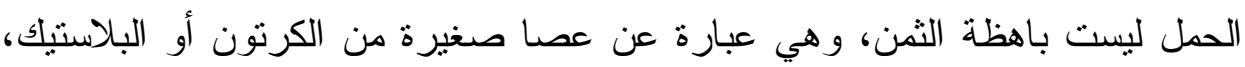

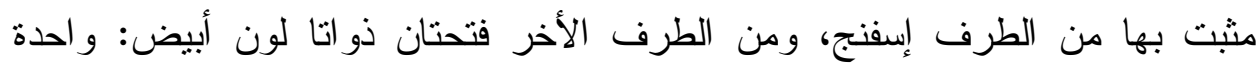

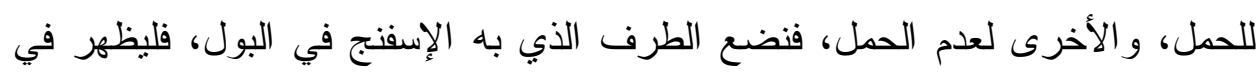

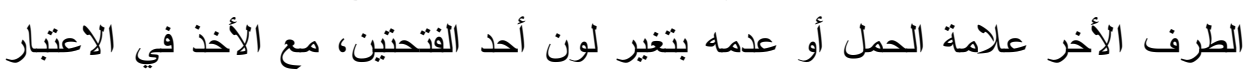
أن يكون البول في الصباح.وهذه الطريقة لا تحتاج للذهاب للطبيب كما أنها تحصل فلئل

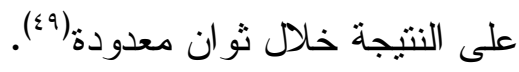
الطريقتان السابقتان يمكن معرفة الحمل بهما وهناك طعرديقة طئة أخري يمكن معرفة جنس الجنين وعدده من خلال تشخيص الحمل عن طريق جهاز "السونار" من خلال التصوير الإشعاعي للموجات فوق الصوتية، والذي يصور الرحم و الأجزاء المحيطة

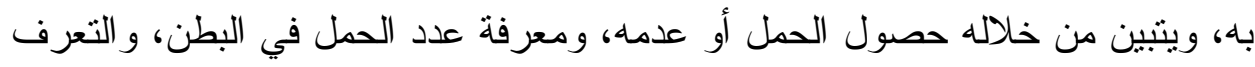

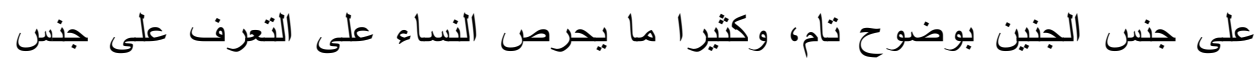
الجنين من خلال عمل هذه الأشعة، فهي تتقل صور الاعضاء ودئ داخل الجسم بدقة ويعتبر الفحص بالسونار في الوقت الحالي أدق وأهم وسائل النشخيص في مجال النساء 
و الو لادة، بذلك امكن تثخيص وجود الحمل في أولى مر احله، كما أمكن معرفة جنس الجنين (0.) - (0)

ويعتمد التصوير بالأمو اج فوق الصوتية على مبدأ إرسال أمو اج فوق صوتية

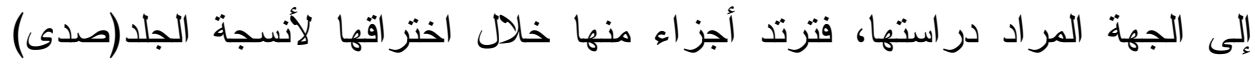

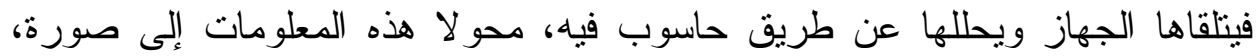
وهو تصوير آمن لا يسبب ضرر اللجنين ويمكن إجراؤه في كل مر احل الحك الحياة الجنينية فمن خلال تلك الأمو اج الصوتية يمكن معرفة جنس الجنين، وقد يحدث خطأ في تمبيز جنس الجنين بسبب عدم تمايز الأعضاء الجنسية بشكل جيد ونسبته أكبر لوكان الجنين خنتى (1) (1)

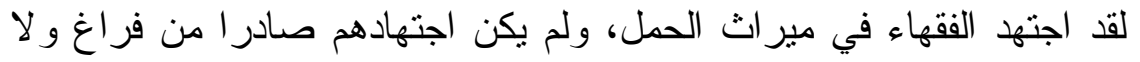

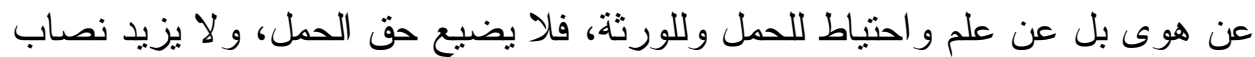

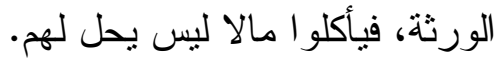
ولكن القرائن الطبية قد أثرت في الميراث إلا أن هذا الثأثثر نسبي، فإذا أثتبت القرائن

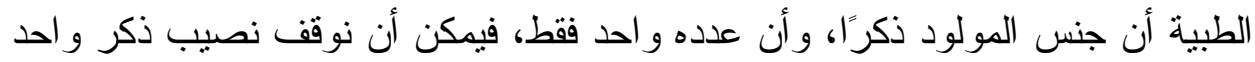

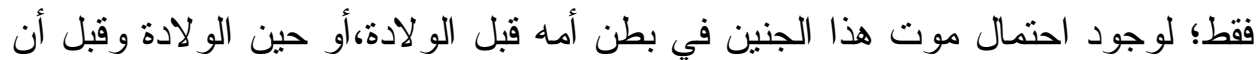

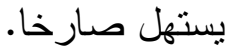
و ولى ذلك تتخف التقديرات الستة التي ذكرها الأطباء إلى تقديرين فقط، على تقدير أنه ميت وعلى تقدير أنه ذكر.

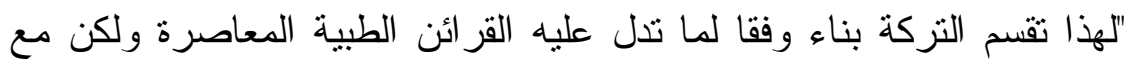

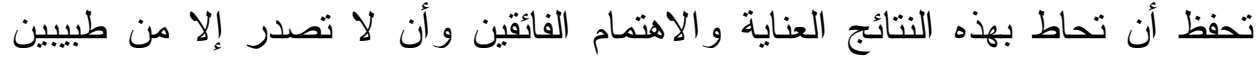

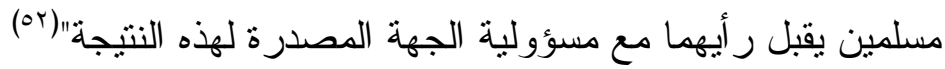


المبحث الثاني: دور القزائن الطبية في إثبات ميراث الخنثى

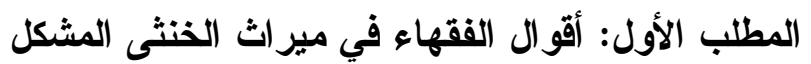

لقد اهتم الفقهاء المسلمون منذ ظهور الإسلام بالخنتى وتمتلى كتب الفقه بقضية

الخنتى، وأحكامها فلابد من تعريف الخنتى.

أولًا: تعريف الخنتى وأهنى

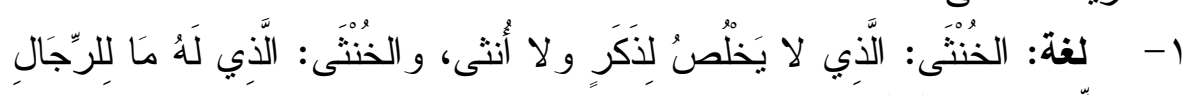

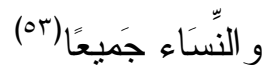

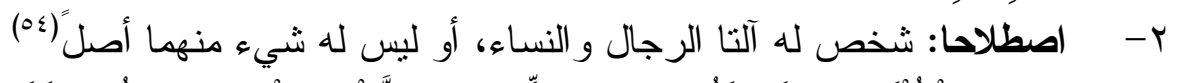

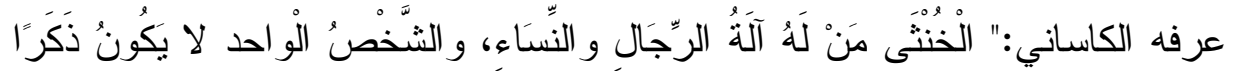

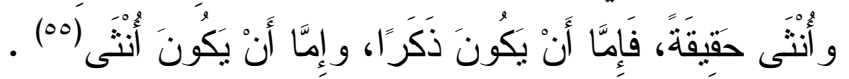

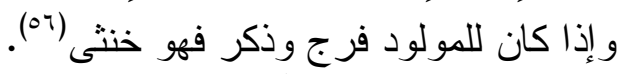

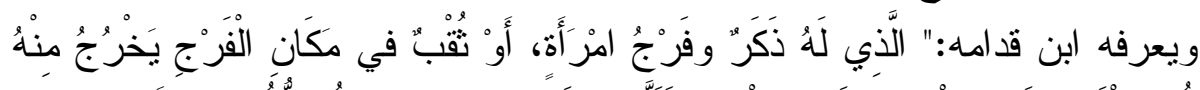

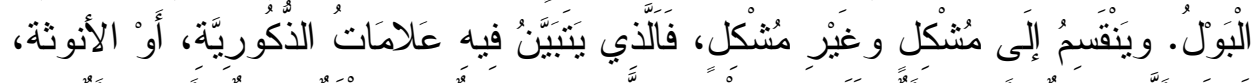

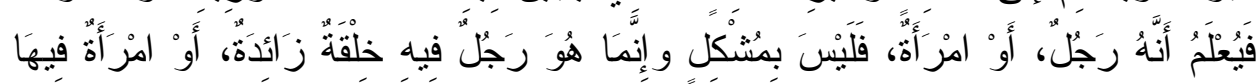

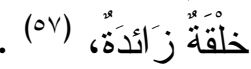

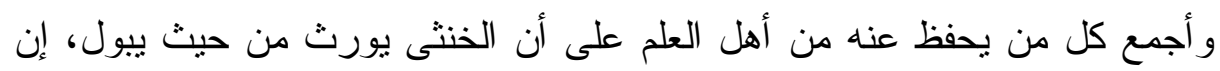

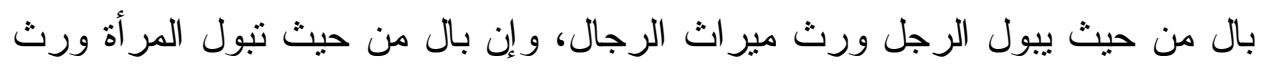

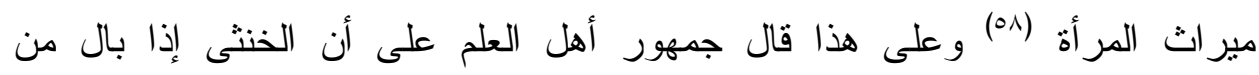
العضوين فحكمه حكم أسبقهما في التبول فإن سبق ببوله من العضو الذكري فهو خنتى الثى ذكر وإلا فهو خنتى أنثى وفي الأول أحكامه أحكام الذكور، وفي الثاني أحكامه أحكام

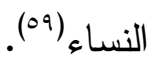

\section{وينقسم الخنتى إلى مشكل وغير مشكل:}

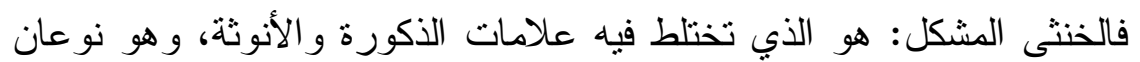

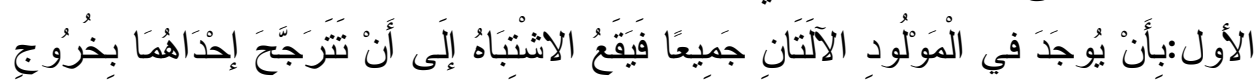
الْبَوْلُ منْهُ.

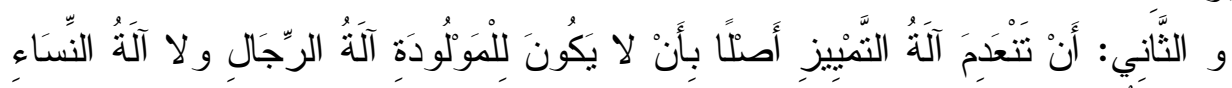

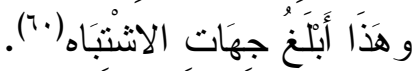




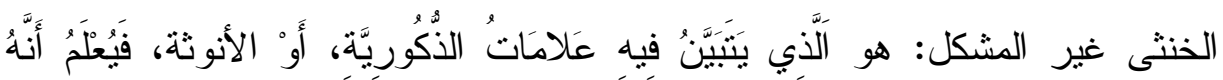

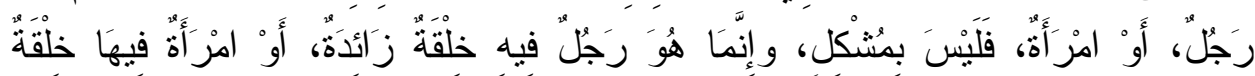

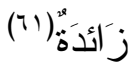

تعريف الخنتى في الطب : رهب

يعرف الخنتى في الكتب الطبية بأنه الثخص الذي تكون أعضاؤه الجنسية الظاهرة غامضة، ولتحديد نوعية الخنتى بنظر الطبيب إلى الغدة التناسلية حسب باتبه

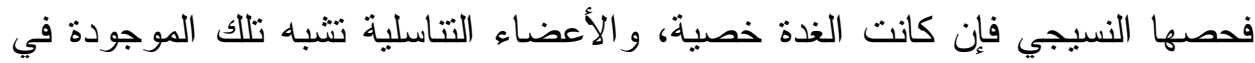
الأنثى، فهو خنتى ذكر كاذب (male pseudo hermaphrodite ) و إن كانت الغدة hermaphrodite) مبيضا و الأعضاء التتاسلية الظاهرة ذكرية فهي خنتي أنتى كاذبة (female pseudo خنتى حقيقة (true hermaphrodite) و لا عبرة بالأعضاء الظاهرة التي قد تشبه

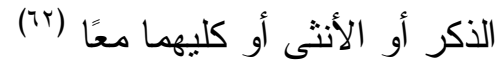

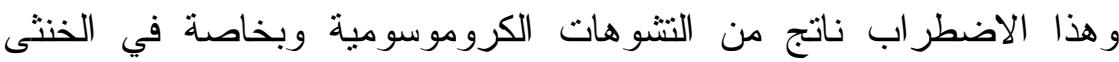
الحقيقة أما الخنتى الكاذبة يكون فيها المريض طبيعيا من الناحية الكروسومية ولكن الاعضاء التتاسلية الخارجية تميل إلى التشابه مع تلك التي تكون في الجنس الأخر وتجري عمليات جر احية لتعديل هذا التشوه (Tr)

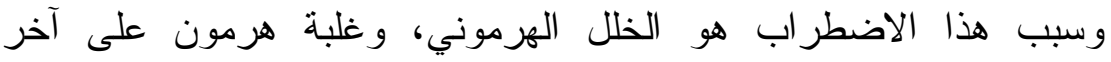

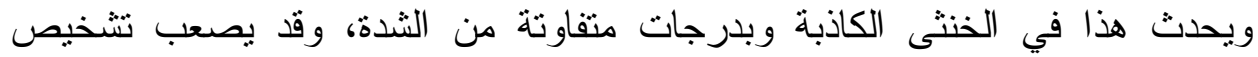
الحالات الخفيفة منها، ومثل هذه الحالات قد تحدث بسبب نقص أو زيادة طبيعية في أحد الهرمونات، أو بسبب العلاج الهرموني للأم الحامل منل تناول هرمون البروجستين

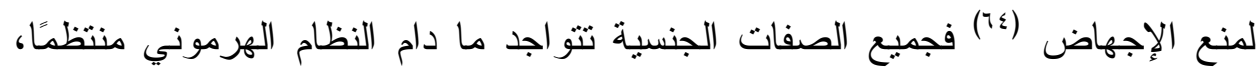
لكن إذا حدث اختلال في النظام الهرموني الجنسي في جسم الكائن الحي سيحدث

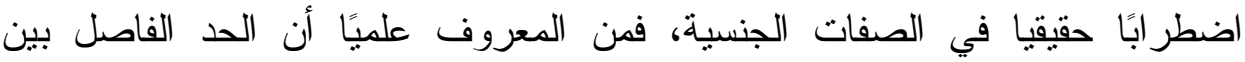

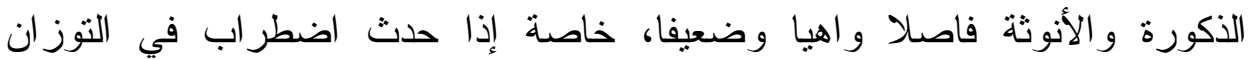

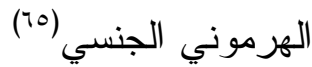

إن العلم يعرف حالات تبدو فيها الصفات الجنسية مختلطة بحيث يغدو من

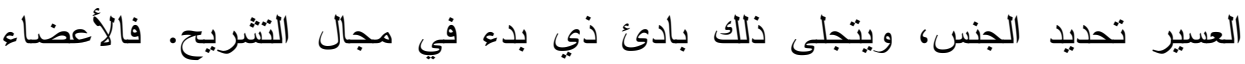


التناسلية لدى هؤ لاء الأشخاص تجمع بين خصائص الذكورة و الأنوثة وفي حالات نادرة

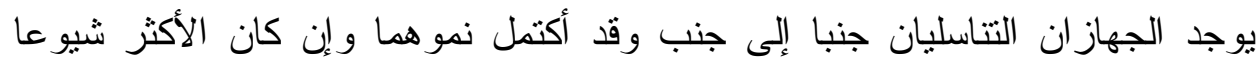

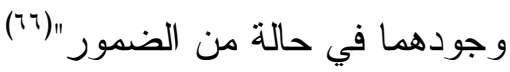
بعد هذا العرض اختلف الفقهاء في مقدار ما يعطى للخنتى في الميراث على أقو ال: - n

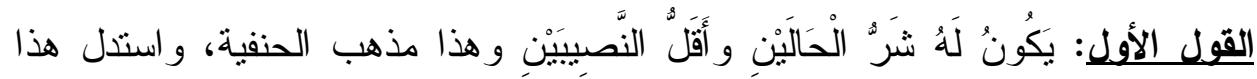

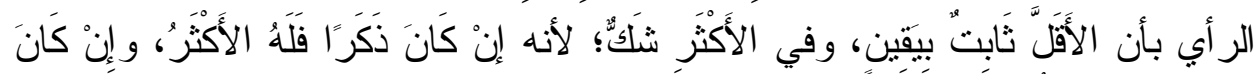

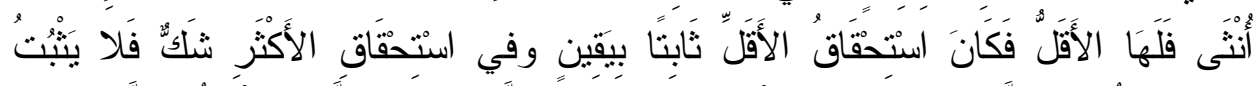

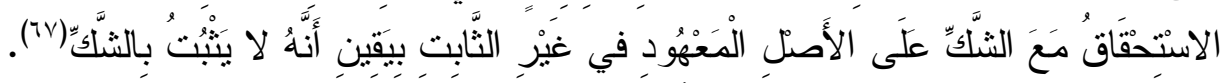

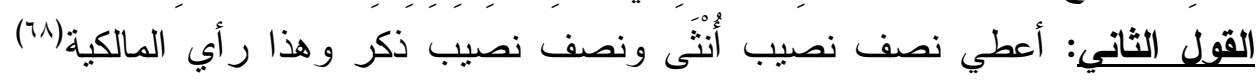

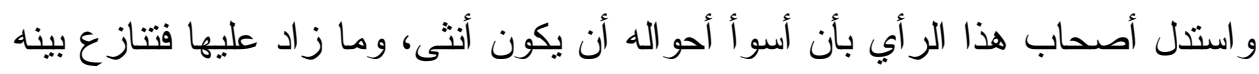

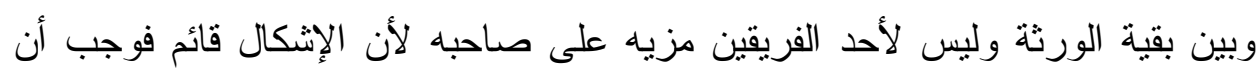
يقسم بينهما كالتداعي (79) القول الثالث: يعامل كل من الورثة والخنتى بأقل النصيبين؛لأنه المتبقي إلى كل منهما

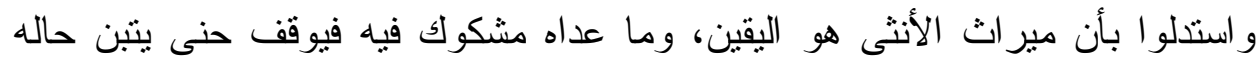
وقالت بـ الثافعية. القول الرابع: قالت به الحنابلة ورأى أبو يوسف من الحنفية إن كان يرجى ظهور

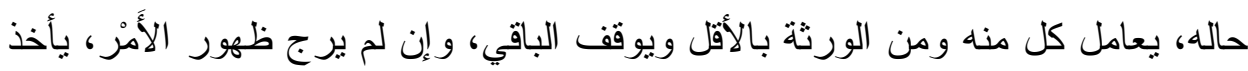

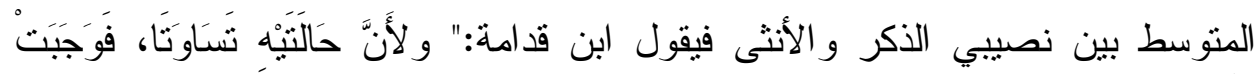

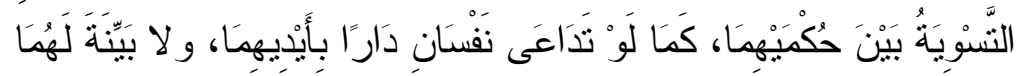

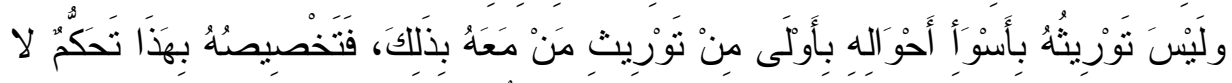

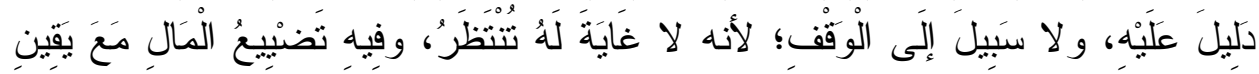

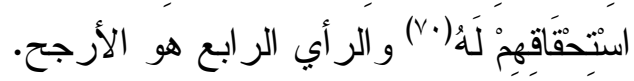
ولكن القانون يأخذ بر أي أبي حنيفة، ففي المادة "ج؟؛" منه للخنتى المشكل، وهو الذي الذي

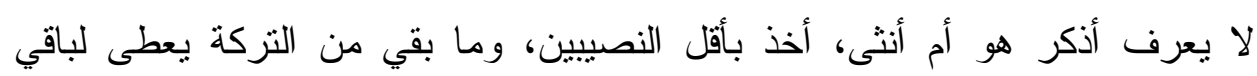

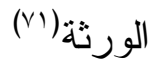


المطلب الثاني: دور القرائن الطبية في إثبات الخنثى المشكل

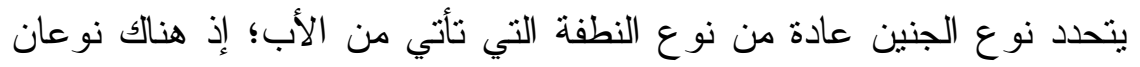

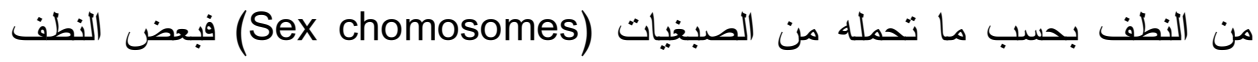
تحمل الصبغ (Y) وبعضها يحمل الصبغ (X) أما بويضة الأم فتحمل نوعا واحدا من

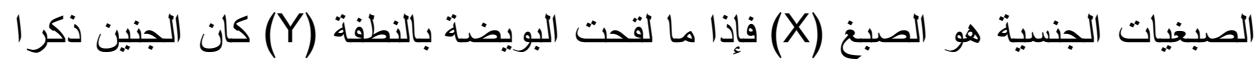
بأذن الله تعالى، و إذا ما لقحت البويضة بالنطفة (X) كان الجنين أنثى.

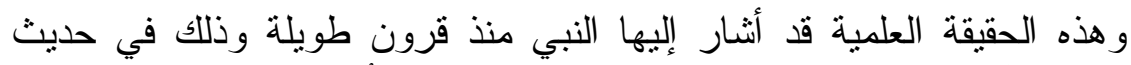

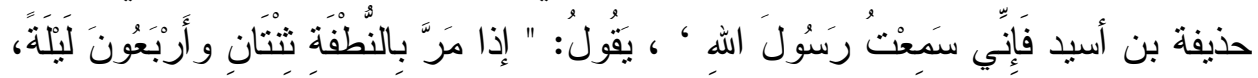

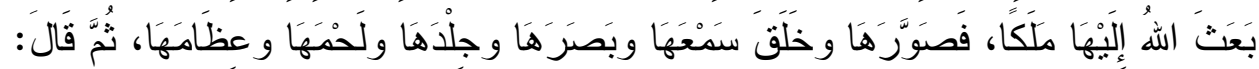

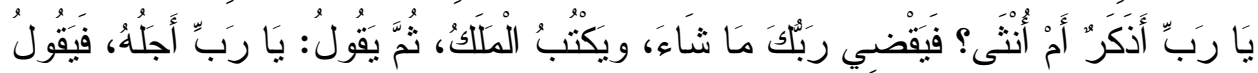

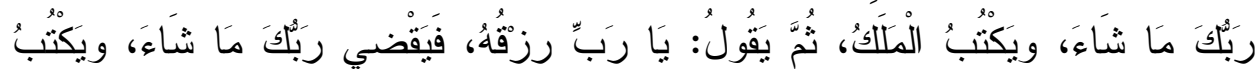

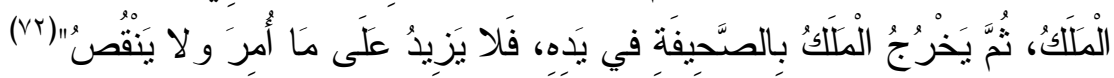

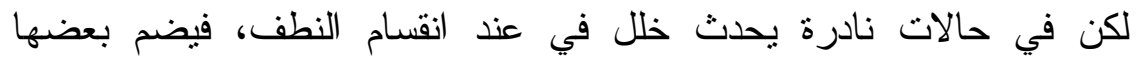
صبغنين جنسيتين (XX) بدل صبغي واحد، بينما يبقى الأخر خاليا من أي صبغي

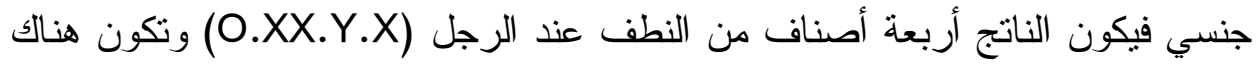
فرصة لانجاب أربعة نركيبات من الأولاد من هذا الرجل بعضها خنتى،على التهل التفصيل التالي: - n

الأول (YO) و هذا لا يعيش عادة

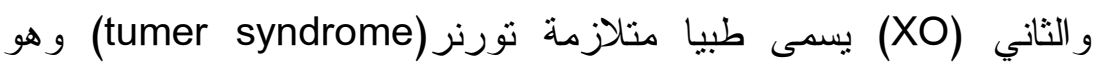
مخلوق ظاهره أنتى ولكنه بلا مبيضين، ويكون مصابا بعدد من التشوهات

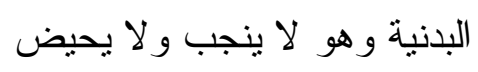

و الثالث (XXO) يسمى طبيا متلازمة كلا ينفلتر (

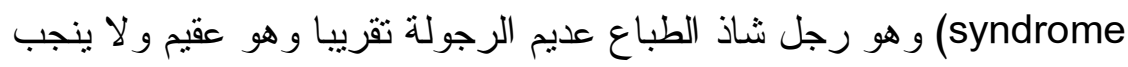

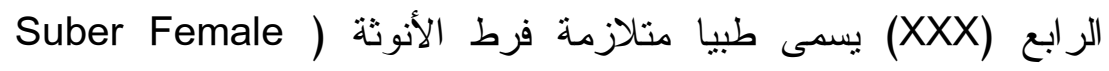

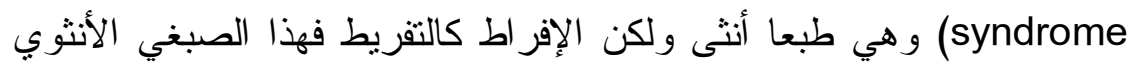

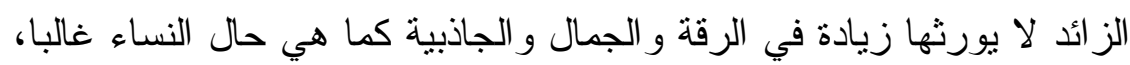
بل على النقيض من هذا نجد أن بعض هذه الحالات متخلفة عقليا أو مصابة 
بندرة الطمث أو انقطاع الطمث، وقد تكون بعض المصابات بهذه المتلازمة طبيعيات تمامًا (VT)

و الأطباء اليوم أقدر على التمييز بين حالات الخنوثة المختلفة ودرجاتها فمن

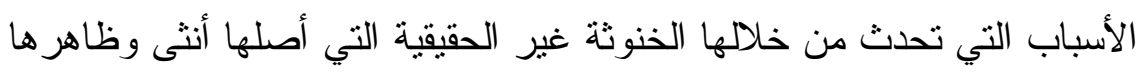

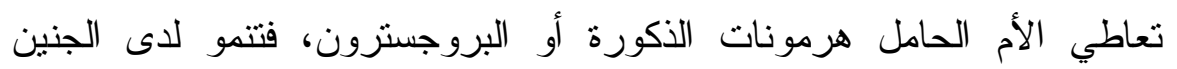

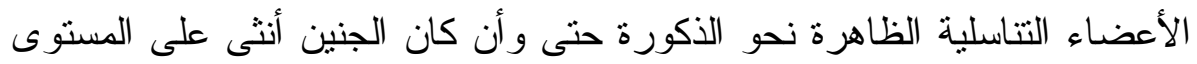

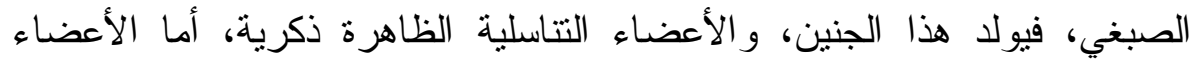
النتاسلية الداخلية فهي أعضاء أنثنية طبيعية. أما الأسباب التي تحدث من خلالها حالات الخنوثة غير الحقيقية التي أصلها

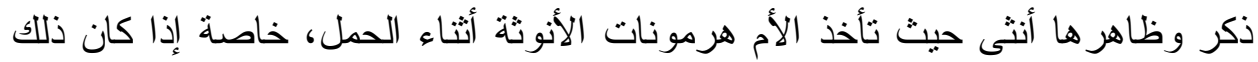

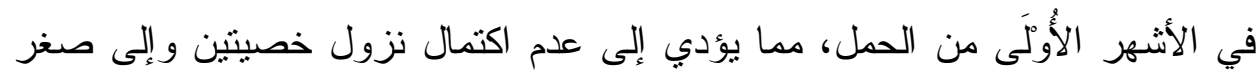

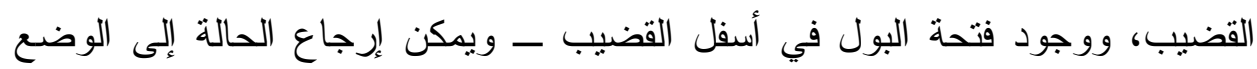

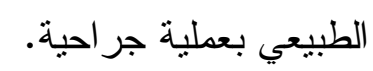
المطلب الثالث: أثر القرينة الطبية في تقسيم ميراث الخنثى :

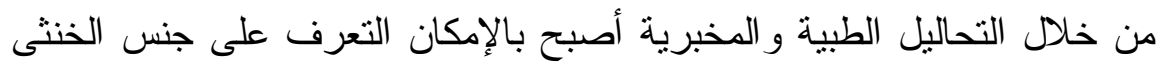
المشكل و إعادنه إلى وضعه الطبيعي المقارب لحالته و الجزم بأنه ذكر أو أنثى من دون الإنى الانتظار حتي يصل إلى سن البلوغ. وفي حالة عدم اكتثاف الحالة إلا بعد سن البلو غُ فإن إن صفات الذكورة أو صفات

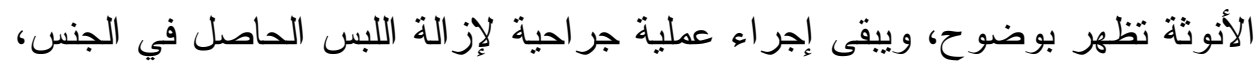

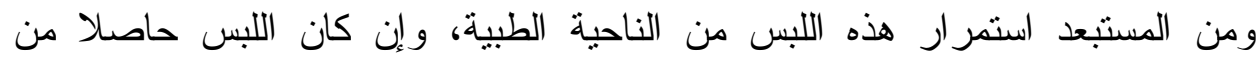

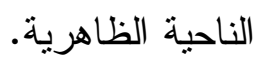

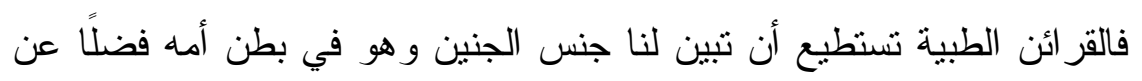

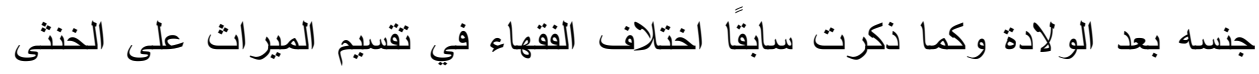

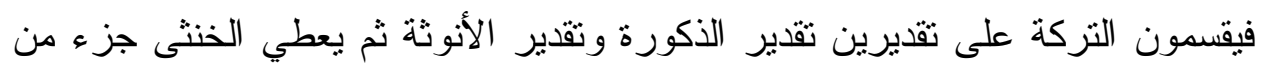

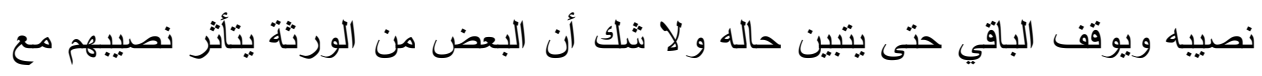

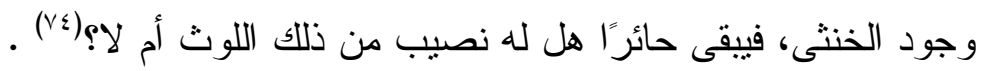


ومن هنا جاء دور القرائن الطبية في تثبيث الحكم الثرعي حيث بينت جنس الخنتى حديث الولادة من خلال عمل بعض الفحوصات المخبرية التي تبين جنسه

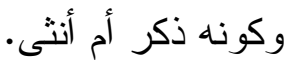

وفي هذا عند تقسيم التركة بعتمد على ما توصلت إلبه القرائن الطبية في تحديد جنس الخنتى وان يعتمد على قول اثثين من الأطباء العدول المتخصصين في هذا الثنأن

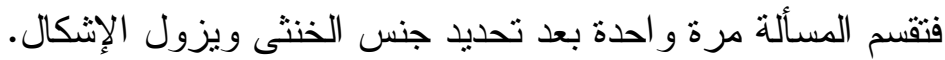

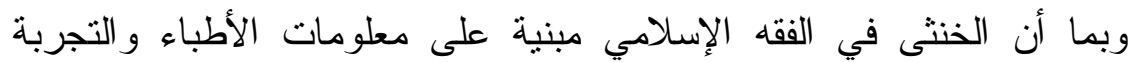

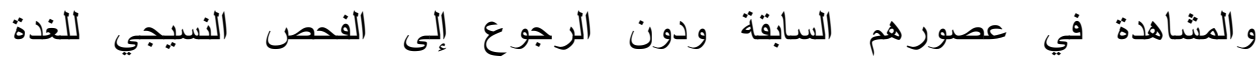

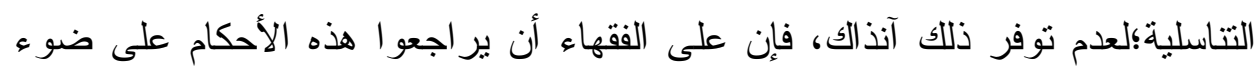
التقدم الطبي الواسع الذي حدث في العصر الحديث.و لابد لذلك اجتماع الأطباء المرتمين

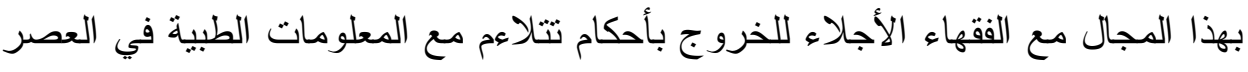

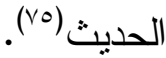


المبحث الثالث: دور القرائن الطبية في ميراث الغرقى والهدمى

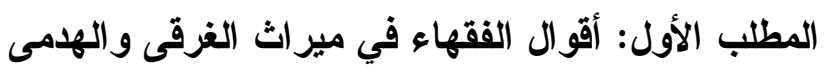

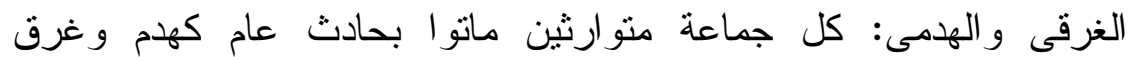
ونحو هما (vi)

وينطبق على كل من عمي موتهم، وجهل المتقدم من المتأخر في الموت، فلم

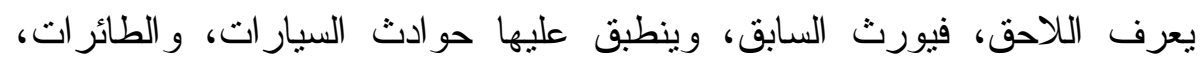
و الانفجار ات، و الأمر اض العامة و المعارك.

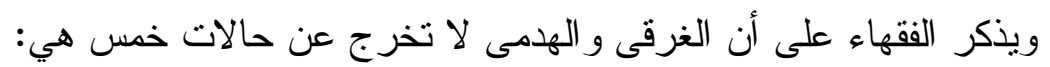

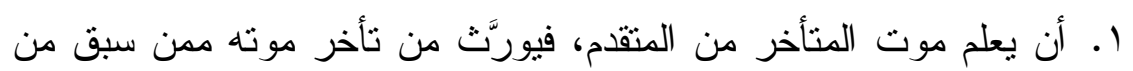
أقاربه.

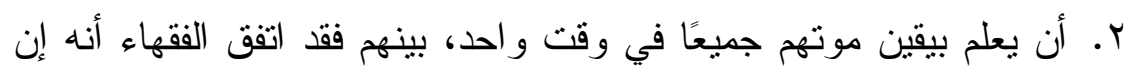

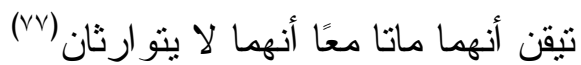

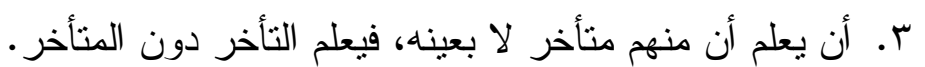

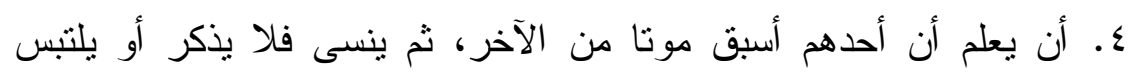
تحديده ه. أن يجهل موتهم، فلا يعرف هل ماتو ا جميعًا في وقت و احد أم تأخر موت بعضهم عن بعض.

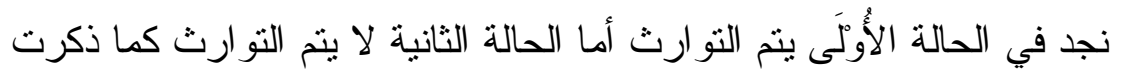

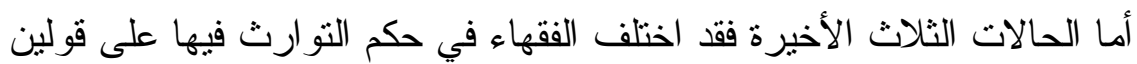
القول الأول: يتم التوارث بين الغرقى والهذمى ومن في صفتهم وقالت به فيه

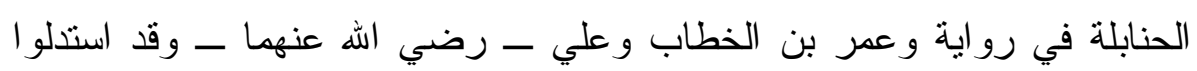
ببعض الأدلة منها:

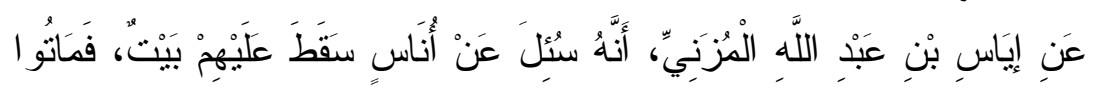

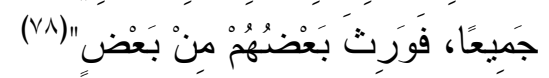

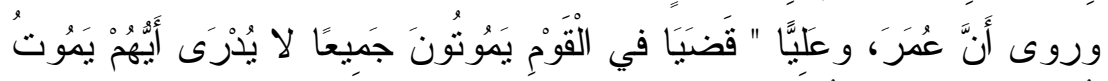

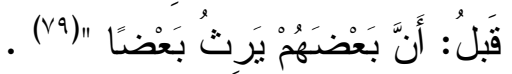


القول الثاني: أن الغرقى و الهمىى لا يرث بعضهم بعضًا وهو قول الجمهور من

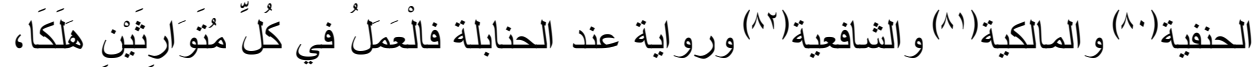

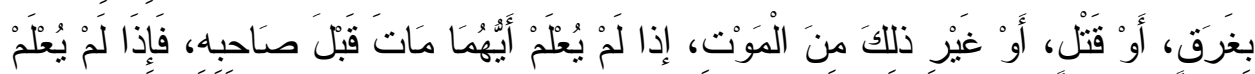

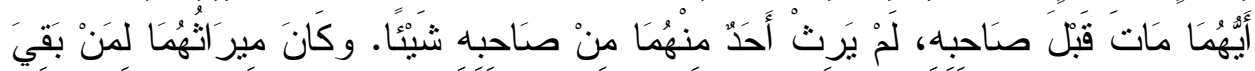

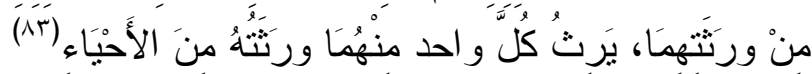
وقد استدلو ا ببعض الأدلة منها:

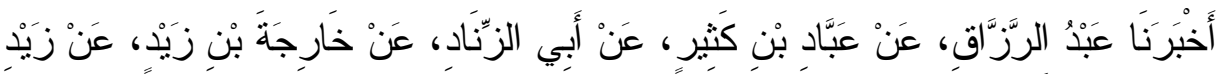

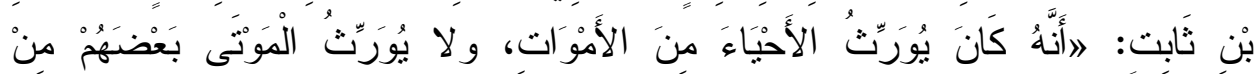

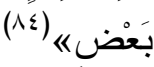

عمل الصحابة حيث انهم لم يورثو امن قتل يوم الجمل، ويوم صفين، ويوم الحرة.(10)

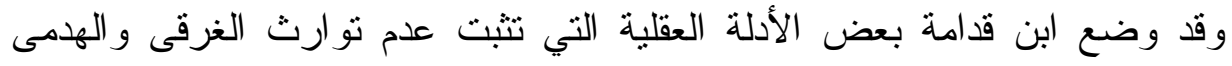

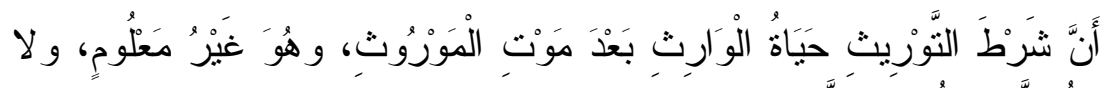
وهي:

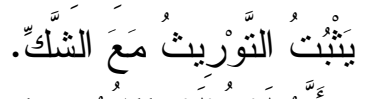

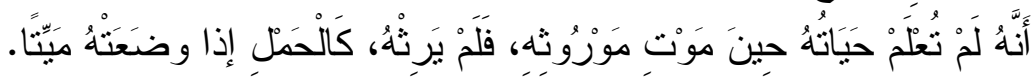

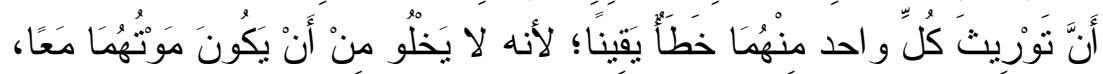

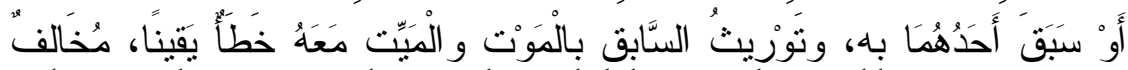

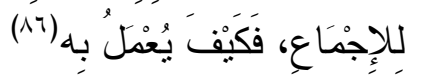

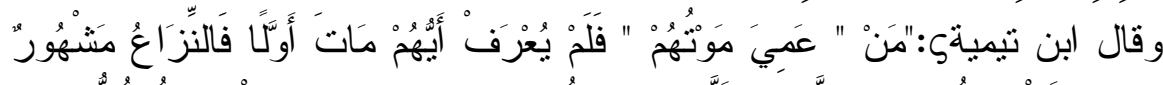

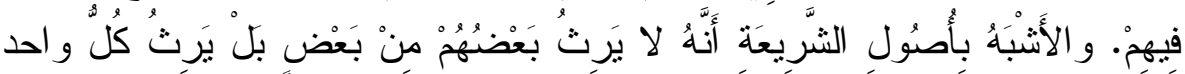

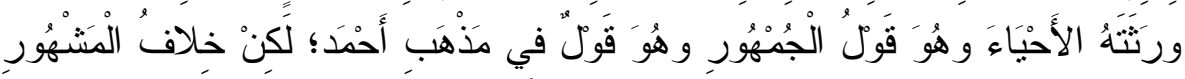

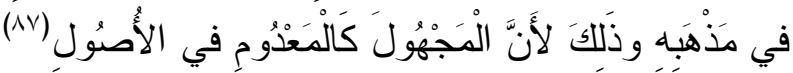

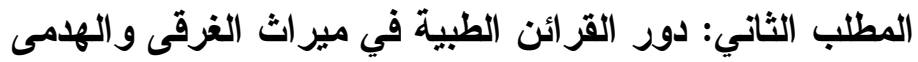

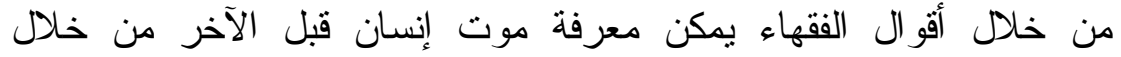

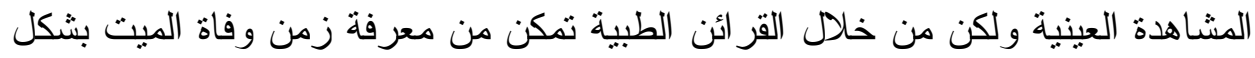

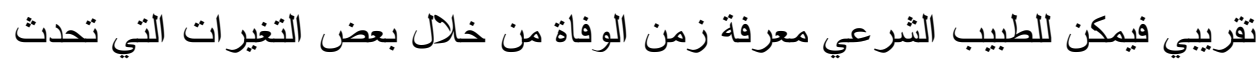
للميت منل: 
( أ ) برودة الجسم: بعد الوفاة تتوقف عمليات الأكسدة الحيوية، ويفقد الجسم

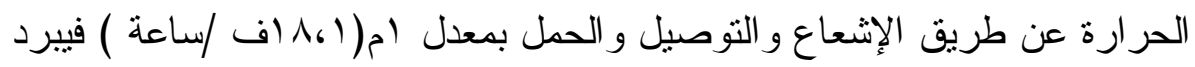

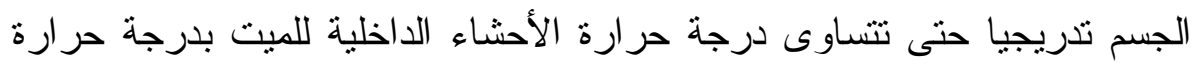

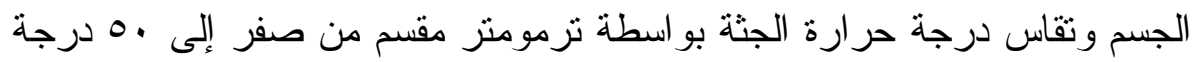

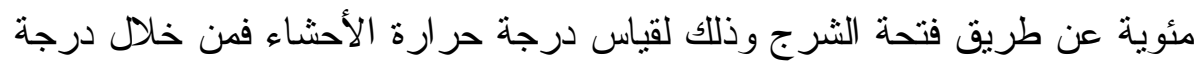

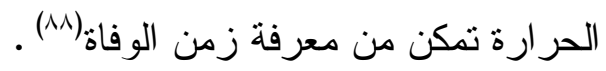

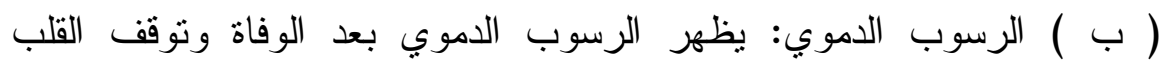

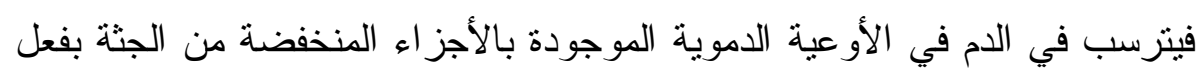

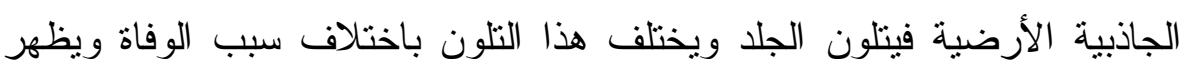
اللون بعد حو الي نصف ساعة إلى ساعة من الوفاة على هيئة بقع تكبر تدريجيا

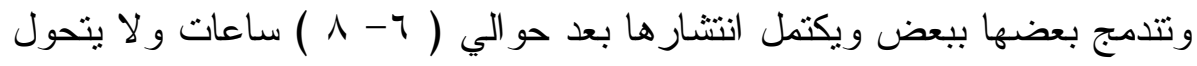
من مكانه بتغيير وضع الجثة نتيجة تكسر كر ات الدم وتسربها من الأوعية الدموية

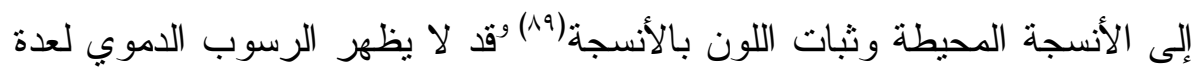

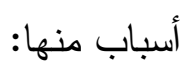

- - - مالات الحروق الثديدة، الجثت المحروقة احتز اقا شبه كامل

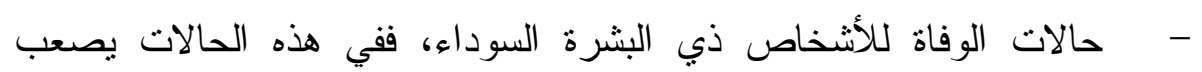
تحديد الرسوب الدموي أو مشاهدته على الجلد.

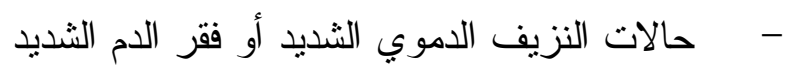
- - مالات الوفاة بسبب تجرثم الدم (sepsis) حيث في تللك الوفيات يتخثر الدم

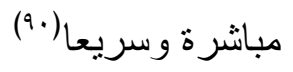
( ج ) التيبس الرمي: يقصد بالتيبس الرمي تصلب العضلات الإر ادية و اللاإرادية للميت نتيجة تحلل كيميائي وتلف مادة ثالث فوسفات الأدينوزين ( P- T-A) ويمكنا التيبس من معرفة وقت الوفاة حيث يبدأ التيبس بعد ساعتين من الوفاة في عضلات الوجه ( بحيث يصعب إغلاق الجفون والفكين) و العضلات الصغيرة

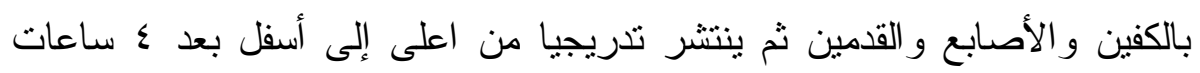

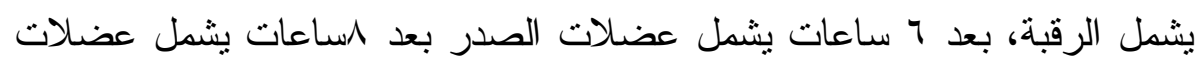

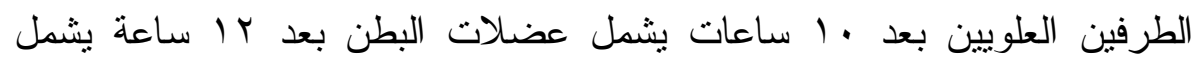


عضلات الطرفين السفليين وبذلك يكون شمل عضلات الجسم كله بعد ؟r ساعة يبدأ التليبس في الزو ال تدريجيا بنفس التزتيب الذي ظهر حتي يزول نمامًا ويصبح

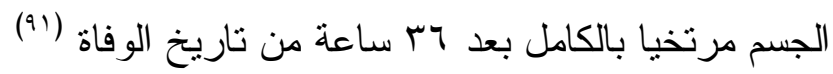

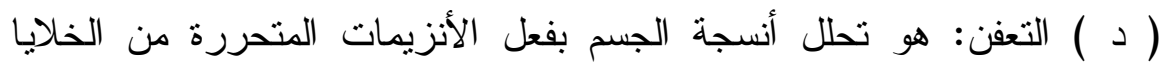
و الجراثيم التي يعيش معظمها في الأمعاء إلى غاز ات وسائل وأملاح يبدأ التعفن

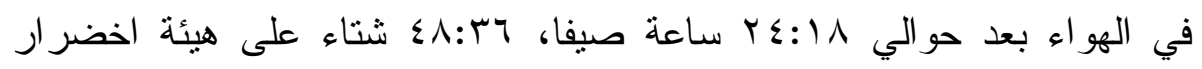
بالجزء السفلي الأيمن من جدار البطن والصدر ثم الرأس والأطر اف وبعد يومين

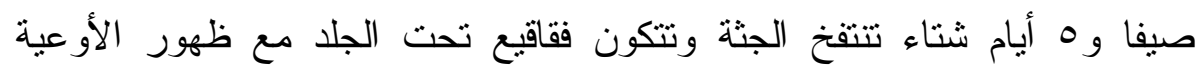
الدموية على هيئة فروع الشجرة بسطح الجلا نتيجة تكون غاز ات التعفن الكريهة

بعد آثهور صيفا و 7 شتاء نجد الهيكل العظمي بدون انسجه متصل بالأربطة بعد 1 شهور صيفا و r شتاء تتآكل الأربطة الموصلة بين العظام عند المفاصل

ونجد عظام مفككة(Tr)

( هـ) التدويد: عندما تتكون غاز ات التعفن وتتبعث من الجثة الرائحة الكريهة

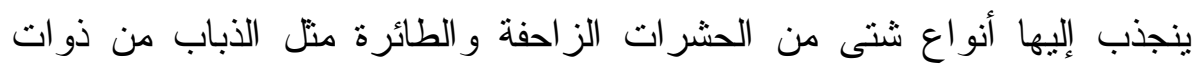

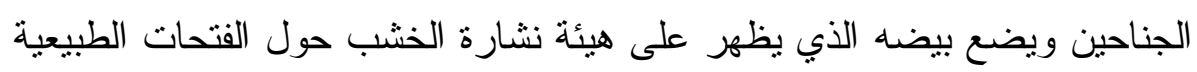

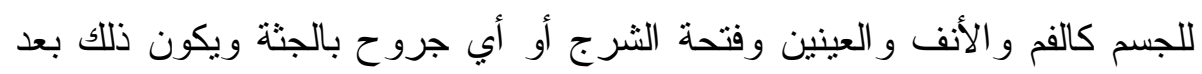
يومين من الوفاة ثم يفقس البيض ويتحول إلى ديدان وتتخذى هذه الديدان على الى ولى

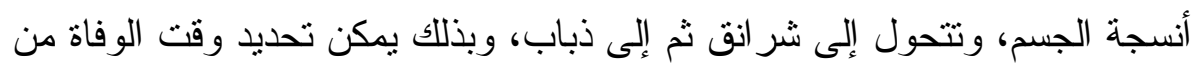

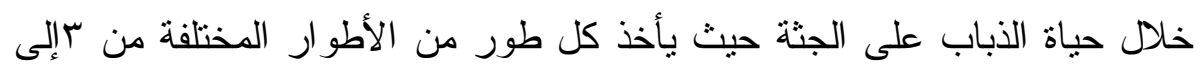
ع أيام تقريبا(بهو) ( و ) التصبن الثمعي: وهو يحدث بدل من التعفن للجثث الموجودة في الماء

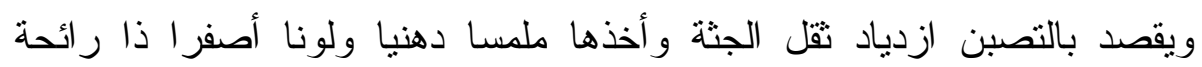
كرائحة الجبن العفن نتيجة تحول الأنسجة الدهنية بالجثة إلى مادة شمعية صلبة التهادية

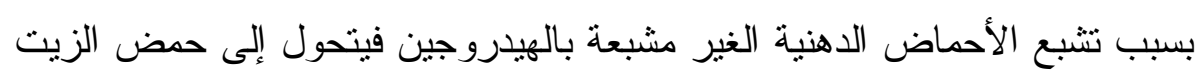

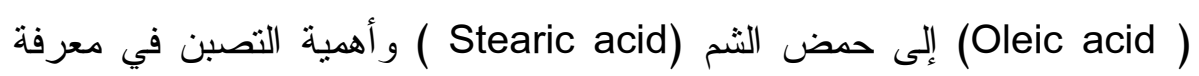
وقت الوفاة التقريبي حيث يبدأ التصبن بعد بالجثة بعد r أسابيع من الوفاة ويكتمل 
في خلال ب:7 أثنهر وكذلك يمكن معرفة الثخص المتوفي من خلال ملامح وجها

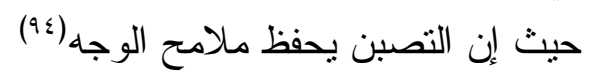
( ز ) التحنيط الطبيعي: تحدث هذه الظاهرة بدلا من التعفن في الجثث الموجودة في وسط شديد الجفاف منل الصحر اء فتتبخر السوائل من الجثة وتموت البكتريا وتتحول الجثة إلى مومياء وأهمية التحنيط الطبيعي يمكن تحديد الوفاة من خلاله

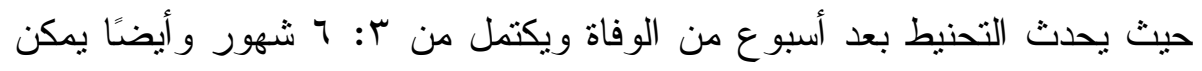
معرفة الثخص لعدم تغير ملامح الوجه بالتحنيط وأيضًا مكان الوفاة وكذلك منك

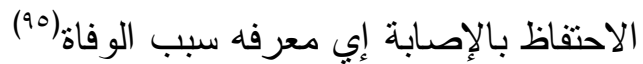

من خلال العرض السابق نجد أهمية القرائن الطبية السالفة الذكر في تحديد زمن الوفاة، فيتم التوارث بين الغرقى و الهذمى متى تمكن الطب الشرعي من تحديد

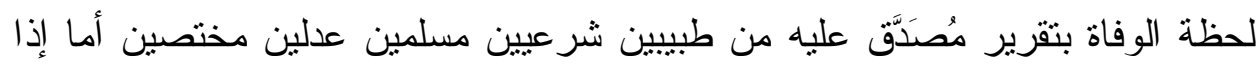

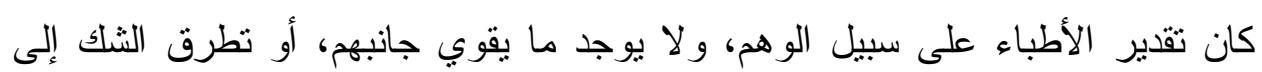

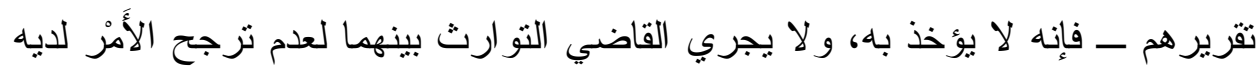

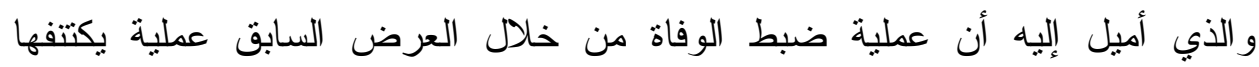

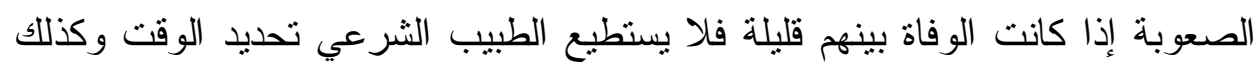

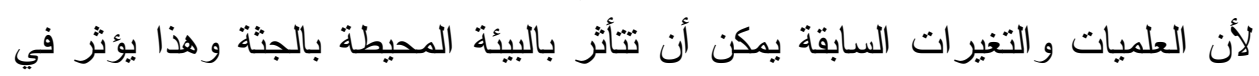
الوقت الذي وضعه العلماء لتحديد كل هذه التغيرات. 


\section{الخاتمة}

\section{من خلال البحث نوصلت لبعض النتائج و التوصيات منها : أولاً: النتائَج : أبحن}

العمل بالقرائن الطبية له أهمية عظمي لا يستطيع أحد إنكار ها لا سيما في

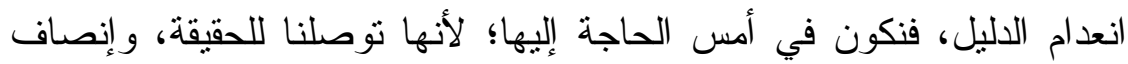
المظلوم. - (المدام العمل بالقرائن يحتاج إلى رجحان العقل، وصفاء الذهن، والتثبت فيها، وعدم التعجل في الحكم بها. إن القرائن في النظام القضائي الإسـاهي ليست مقصورة على القرائن الثرعية؛ بل تشمل كل أمارة بمكن استتباطها. إن حقائق العلم التجريبي حقائق شرعية، يتعين اعتبارها من جملة الأدلة الثرعية؛ حتى لا يخالف الثرع المنطق و العقل، ما دامت هذه الأدلة قطعية الثبوت، و لا تحتمل الخطأ. ثانيًا: التوصيات :

دعوة الباحثين و المجامع الفقهية والهيئات العلمية إلى دراسة ما استجد من قرائن طبية؛ كالفحص الوراثي، وبصمات الأجزاء الحيوية المختلفة، وبيان مدى قوتها في جانب الإثبات القضائي. الدعوة إلى الاهتمام بالطب و وانشغال المسلمين به؛ حتى يبني الإبات الفقهاء الأحكام

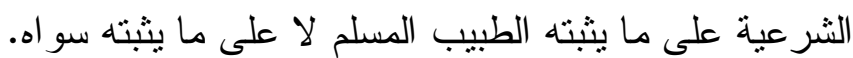

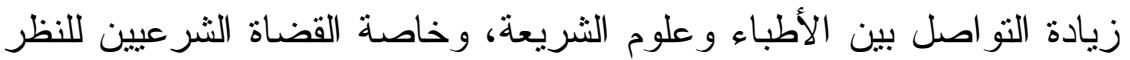

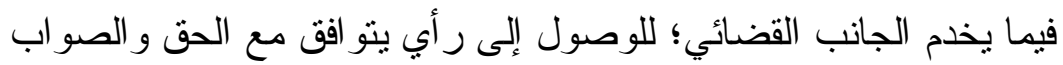

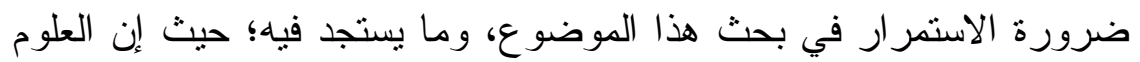
الطبية كل يوم فيها جديد، و الفقه الإسلامي فقه مرن يحوي كل ما يستجد. 


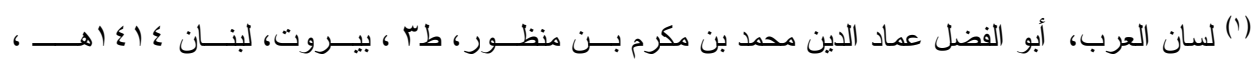
r) $\leq / 1$

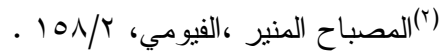

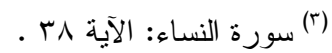

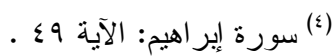

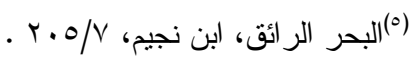

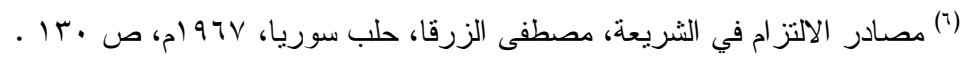

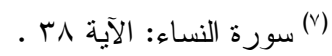

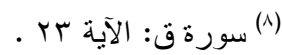

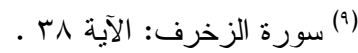

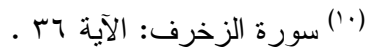

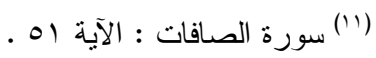

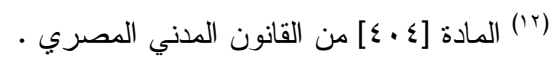

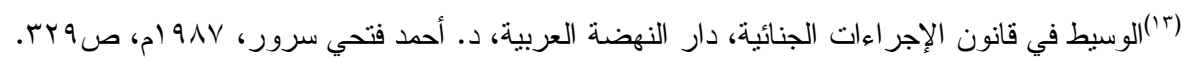

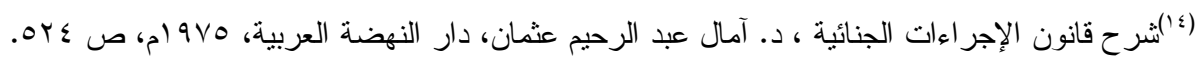

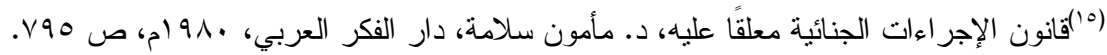

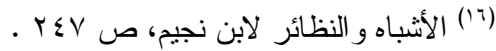

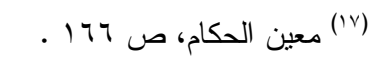

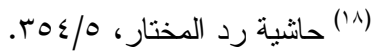

(9) تبصرة الحكام في أصول الأقضية ومناهج الأحكام، إبر اهيم بن علي بن محمد، ابن فرحون، برهــان الــدين

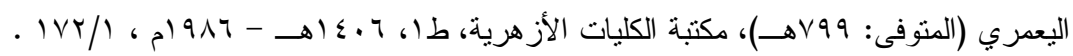

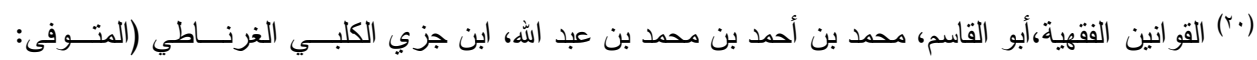
$(\rightarrow \vee \leq)$ ص ص

(اיا) الجامع لأحكام القرآن، أبو عبد الهه محمد بن أحمد بن أبي بكر بن فرح الأنصساري الخزرجي شــمس الــدين

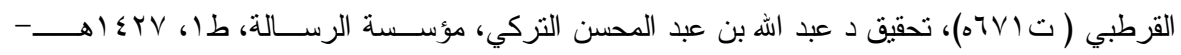

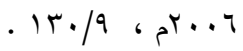

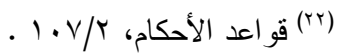

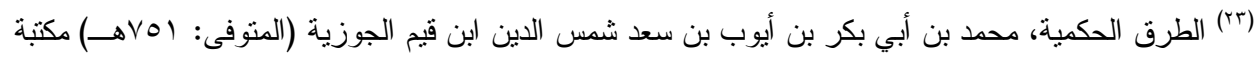

$$
\begin{aligned}
& \text { دار البيان ، 1/ع . } \\
& \text { (r\&) تبصرة الحكام، }
\end{aligned}
$$


(ب)

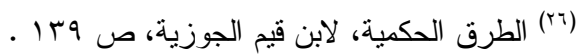

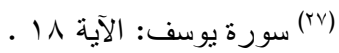

$$
\begin{aligned}
& \text { (r) } \\
& \text { (r9) ينظر : المرجع السابق. (rq) }
\end{aligned}
$$

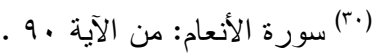

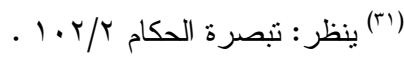

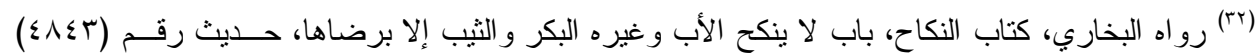

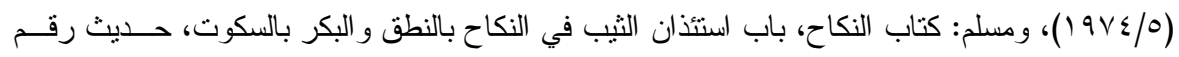

$$
\begin{aligned}
& \text {. 1. } 14 / r(1 \leq 19)
\end{aligned}
$$

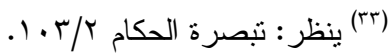

$$
\begin{aligned}
& \text { (؟) ينظر : المغني } \\
& \text { (ro) }
\end{aligned}
$$

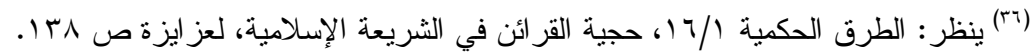

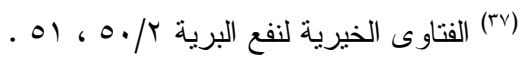

$$
\begin{aligned}
& \text { قرة (r) }
\end{aligned}
$$

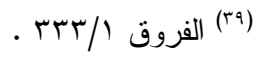

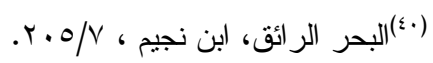

(اء) رواه البخاري في التفسير ، باب: ويدرؤوا عنها العذاب أن نتهد أربع شهادات باله إنه لمن الكاذبين، حديث

$$
\text { رقم })
$$

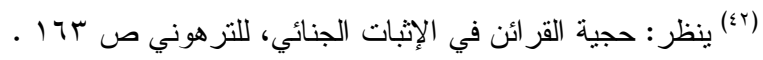

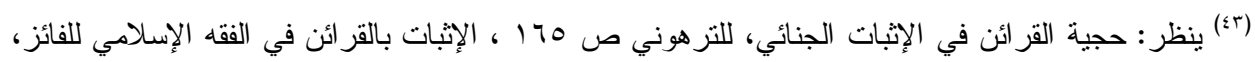

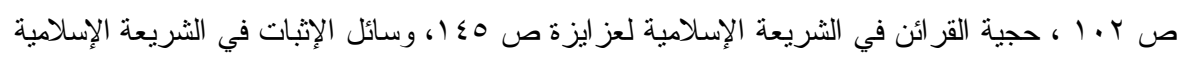

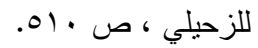

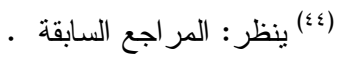

$$
\begin{aligned}
& \text { (؛) ينظر : المر اجع السابقة. }
\end{aligned}
$$

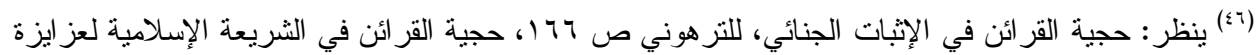
. $1 \leqslant \wedge$

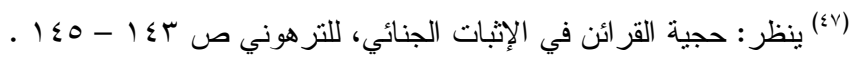

$$
\text { Or/ المبسوط للسرخسي، }
$$

(9ء) أثر الثقنية الحديثة في الخلاف الفقهي، هثام بن عبد الله بن محمد آل الثنيخ. رسالة دكتور اه، المعهد العالي

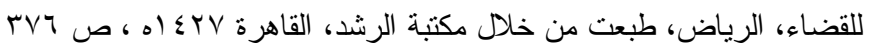




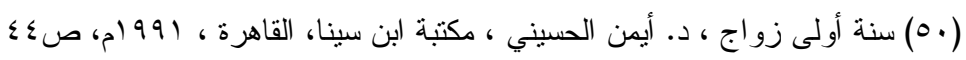

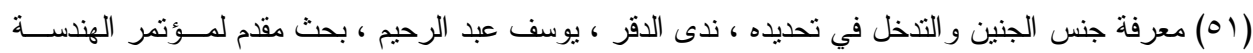

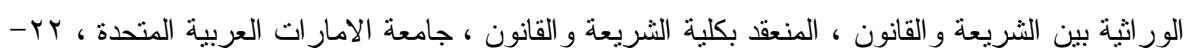

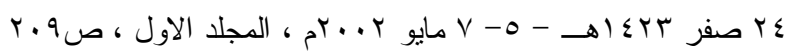
(ro) الموسوعة الميسرة في فقه القضايا المعاصرة (قسم فقه الأسرة) إعداد مركز التميز البحثي التابع لجامعة

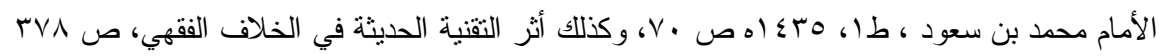

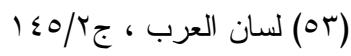

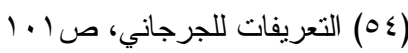

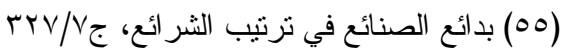

(7ه) البناية شرح الهداية، أبو محمد محمود بن أحمد بن موسى بن أحمد بن حسين الغيتابى الحنفي بدر الــدين

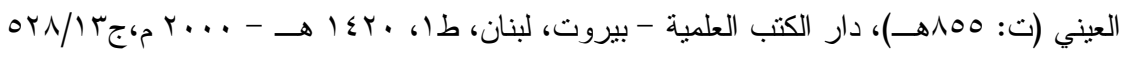

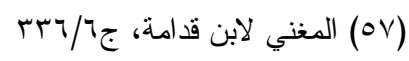

(01) الإقتاع في مسائل الإجماع، علي بن محمد بن عبد الملك الكتامي الحميري الفاسي، أبو الحسن ابن القطان

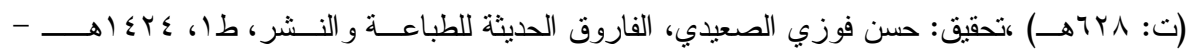

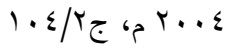

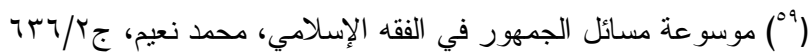

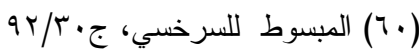

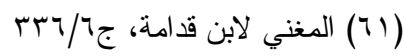

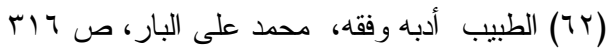

(ז7) الور اثثة و الإنسان ، أساسيات الور اثثة البشرية و الطبية ، مصطفى ناصف، سلسلة عالم المعرفة تــصدرها

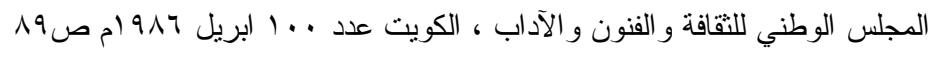

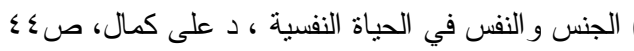

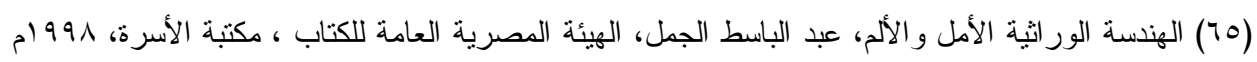

ك

(77) ثلاث مقالات في النظرية الجنسية "سيجموند فرويد" ترجمة سامي محمود على ر اجعها مصطفى زيــور،

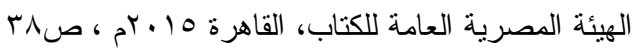

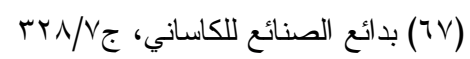

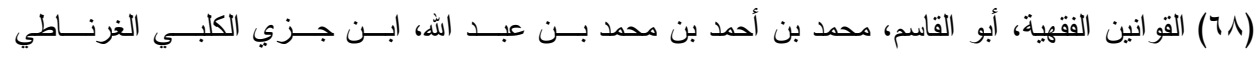

$$
\text { r }
$$

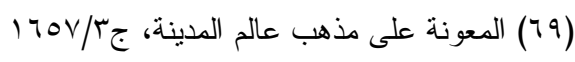

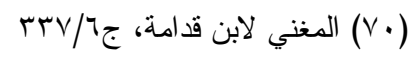




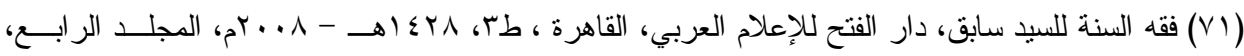
ص ص

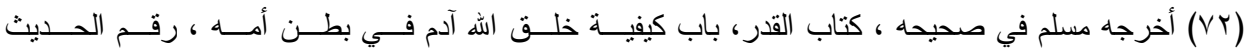

$$
r \cdot r V / \varepsilon ج(r r \leqslant 0)
$$

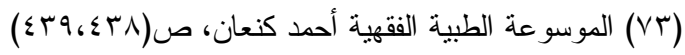

( أثر التقنية الحديثة في الخلاف الفقهي، ص ع (V乏)

(Vo) الخنثى بين الطب و الفقه ، محمد على البار بحث بمجلة المجمع الفقهي الاسلامي ، السنة الر ابعــة العـدد

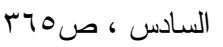

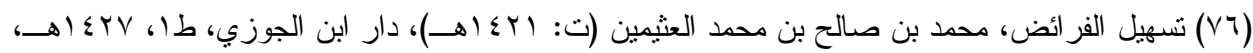

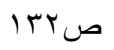

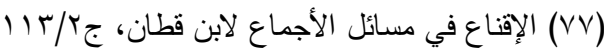

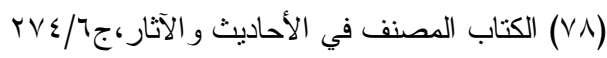

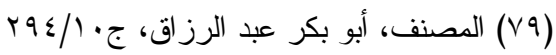

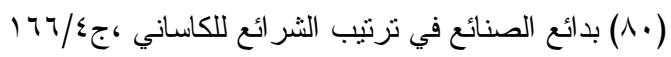

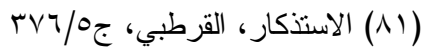

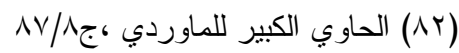

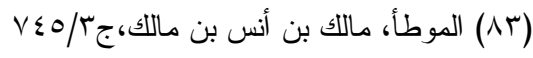

$$
\text { r }
$$$$
\text { v }
$$

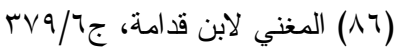

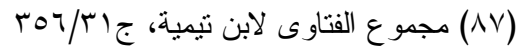

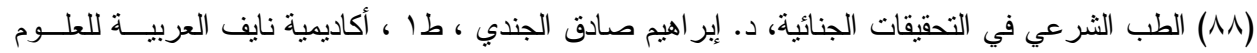

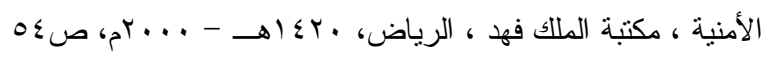

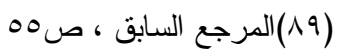

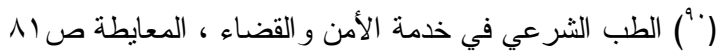

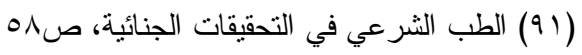

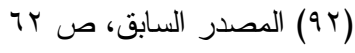

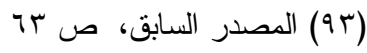

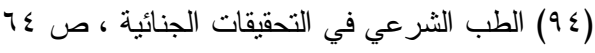

$$
\text { (90) نفس المرجع ، ص10 (10) }
$$


